\title{
UWAGI DO DATOWANIA I PERIODYZACJI UŻYTKOWANIA CMENTARZYSKA W DOMASŁAWIU-CHRZANOWIE, POW. WROCŁAWSKI
}

\author{
COMMENTS ON DATING AND THE PERIODIZATION OF THE USE \\ OF THE BURIAL GROUND IN DOMASŁAW-CHRZANÓW, WROCŁAW DISTRICT
}

\begin{abstract}
The paper contains the comments of an archaeologist on the results of dating the Bronze and early Iron Age burial ground in Domasław, Wrocław district by the 14C method. Most of the dates obtained correlate well with previous archaeological dating to the Bronze and early Iron Age. There are, however, a few exceptions (namely, the stylistic characteristics of grave inventories) in which the established typological classification contrasts with the radiocarbon dates determined for these features and situates them much earlier, largely during the period of the Tumulus cultures in Polish territory in the II period of the Bronze Age in the periodization by O. Montelius/J. Kostrzewski and BC and BD in the southern periodization system. Similarly, several other assemblages from the youngest phase of the use of the burial ground from the HC period obtained much older dates.

KEY WORDS: Domasław, Lower Silesia, cremation burial ground, the Bronze Age, the early Iron Age, absolute dating ${ }^{14} \mathrm{C}$
\end{abstract}

Po wyczerpującej prezentacji i omówieniu metodyki oraz wyników datowania ${ }^{14} \mathrm{C}$ kości z Domasławia dokonanej przez Profesora Tomasza Goslara, pochodzących ze zbadanych grobów ciałopalnych na cmentarzysku usytuowanym na terenach dwóch gmin - Domasławia i Chrzanowa (Anioła et al. 2012), chciałbym krótko przedstawić swoje uwagi jako archeolog na temat osiągniętych wyników. Dzięki środkom pozyskanym w ramach projektu grantowego Narodowego Centrum Nauki: Przemiany w obrzadku grzebalnym w epoce brazu i wczesnej epoce żelaza jako wyraz zmian społeczno-kulturowych $w$ potudniowo-zachodniej Polsce - umowa nr UMO-2014/15/B/HS3/02463 $\mathrm{z}$ dn. 10.08.2015 r., udało nam się podczas jego realizacji uzyskać wyniki specjalistycznych analiz w Laboratorium Analiz Radiowęglowych w Poznaniu datowania bezwzględnego dla 50 próbek $\mathrm{z}$ materiałów kostnych z grobów z cmentarzyska w Domasławiu/Chrzanowie. Jest to w skali polskich badań archeologicznych sukces dużej miary. Nigdy dotąd nie przeprowadzono takich analiz $\mathrm{w}$ tak dużej ilości. Chlubnym wyjątkiem jest neolityczne stanowisko w Bronocicach, dla którego wykonano 
60 datowań ${ }^{14} \mathrm{C}$ (Kruk, Milisauskas, Włodarczak 2018). Jednak wartość pozyskanych wyników ma przede wszystkim olbrzymie znaczenie merytoryczne. Cmentarzysko w Domasławiu/Chrzanowie było użytkowane przez cały czas wyróżnianego w pradziejach Europy okresu pól popielnicowych, a w przypadku naszych ziem wyróżnianej archeologicznej kultury łużyckiej od środkowej epoki brązu po wczesny okres epoki żelaza-halsztacki. Próbki wytypowane do analizy pochodziły z całego tego znacznego przedziału chronologicznego, co ma duże znaczenie. Datowania radiowęglowe z podobnego przekroju chronologicznego wykonane w Laboratorium w Kijowie pochodzą jeszcze z dużego badanego przez wiele sezonów wykopaliskowych przez Profesora Marka Gedla cmentarzyska w Kietrzu, pow. Głubczyce. Badacz ten poświęcił opracowaniu uzyskanych wyników wiele cennych swoich prac (por. Gedl 2002). Obszerny komentarz i omówienie tych wyników analiz radiowęglowych opublikował J. Chochorowski (2007), jest ich jednak o połowę mniej niż uzyskanych wyników z próbek poddanych analizie z cmentarzyska w Domasławiu/Chrzanowie. W obu przypadkach otrzymujemy doskonały materiał do studiów porównawczych i refleksji nad problematyką chronologii, do jakich skłaniają wyniki analiz radiowęglowych. Zanim jednak do nich przejdziemy, należy jeszcze zaakcentować fakt, iż przy obecnym stanie badań w przypadku obu tych zbadanych cmentarzysk mamy do czynienia z obiektami o progowym znaczeniu dla wielorakich studiów nad problematyką obrazu kulturowego naszych ziem, a nawet Europy Środkowej. Z tego też względu uściślanie ram chronologicznych wydarzeń rozpoznawanych na podstawie źródeł pozyskanych w rezultacie badań na obu tych obiektach stanowi znaczące wydarzenie w dziejach naszych badań.

Laboratoryjne analizy radiowęglowe już od kilkudziesięciu lat rodzą nowe możliwości w uzyskiwaniu dat bezwzględnych nie jedynie dla okresów pradziejowych nas $\mathrm{w}$ tym przypadku interesujących. Oczywiście zdajemy sobie sprawę z tego, że wyniki tych analiz nie sprawią, iż pradzieje staną się historią wydarzeniową według porządku dat kalendarzowych, z jaką mamy do czynienia w przypadku tej właśnie pokrewnej nam dyscypliny. Stają się jednak ogromnie ważnym czynnikiem poszerzającym dotychczasowe mozolne trudy archeologów podejmujących problemy chronologii i periodyzacji pradziejów, a w przypadku wielu regionów Świata i Europy także czasów wczesnohistorycznych.

Wyniki badań radiowęglowych, tak w przypadku cmentarzyska w Kietrzu, jak też nas interesującego w Domasławiu, ukazują pewne rozbieżności w datowaniu między datami radiowęglowymi a datowaniem poszczególnych okresów epoki brązu i wczesnej epoki żelaza znanego z systemów periodyzacji dla kręgu nordyjskiego O. Monteliusa oraz południowego P. Reineckiego, modyfikowanych dla ziem polskich przez J. Kostrzewskiego (1965). Ten system J. Kostrzewskiego w zakresie datowania poszczególnych okresów był w latach późniejszych dla poszczególnych regionów ziem polskich, jak też całego obszaru tychże ziem, modyfikowany. Na podstawie wyników badań na niektórych stanowiskach, np. na cmentarzysku w Kietrzu, M. Gedl uszczegółowił i zmodyfikował system periodyzacji (Gedl 1979; 1980) bez wnikania w datowanie wyróżnianych faz funkcjonowania cmentarzyska. W roku 1979 ukazuje się czwarty tom Prahistorii ziem polskich, w którym A. Gardawski prezentuje opracowane przez siebie w tabelarycznym ujęciu systemy O. Monteliusa i P. Reineckiego (Dąbrowski, Rajewski - red. 1979, 24) w zestawieniu z systemem J. Kostrzewskiego z 1965 roku z podaniem datowania wyróżnianych okresów epoki brązu i wczesnej epoki żelaza. W roku 1982 B. Gediga (1982, 49-58, tab. 1) przedstawił próbę periodyzacji i chronologii kultury łużyckiej na Śląsku, uwzględniając porównawczo systemy O. Monteliusa, J. Kostrzewskiego i P. Reineckiego, zbliżoną do wcześniej opublikowanego schematu periodyzacji i chronologii ogólnie dla epoki brązu po początki wczesnej epoki żelaza przez G. Jacoba-Friesena (1973, 641-648). Pozostając jeszcze przy kilku przykładach prezentowanych periodyzacji i chronologii epoki brązu i wczesnej epoki żelaza, aby uzyskać szerszą perspektywę dla dalszych uwag na ten temat w świetle wyników analiz radiowęglowych próbek z grobów cmentarzyska w Domasławiu, przywołać jeszcze można niedawną, bo z 1998 roku propozycję z pierwszego tomu Wielkiej historii Polski pióra J. K. Kozłowskiego i P. Kaczanowskiego (1998, 45). Autorzy wykorzystują wczesne daty uzyskane dla wczesnej epoki brązu, także przede wszystkim w rezultacie analiz radiowęglowych i dość ogólnie rozmieszczając datowanie dalszych okresów tejże epoki. Rok później ukazuje się pierwszy tom z cyklu Encyklopedia historyczna Świata zatytułowany Prehistoria, w którym w rozdziałach poświęconych 
epoce brązu i epoce żelaza J. Chochorowski omawia chronologię na szerszym tle kulturowym, a na stronie 207 zamieszcza ryc. 249 z tabelarycznym zestawieniem chronologii i periodyzacji tego wycinka pradziejów według O. Monteliusa i P. Reineckiego, zaś na stronie 210 na ryc. 251 ukazuje m.in. ramy czasowe występowania kultury łużyckiej w Europie środkowej, rozciągając je zgodnie z najnowszymi wynikami badań na czas od II okresu epoki brązu $\left(\mathrm{EB}^{1}\right)$ po okres lateński Lta B (Chochorowski 1999, 206-210). Na zakończenie tego krótkiego przypomnienia kilku wybranych opracowań chronologii i periodyzacji epoki brązu i wczesnej epoki żelaza głównie w ujęciach syntetycznych warto wspomnieć jeszcze często już przywoływaną syntezę kultury łużyckiej J. Dąbrowskiego (2009, tab. 1) w ujęciu naukowo-popularnym, w którym znajdujemy na s. 17 tabelę $1 \mathrm{z}$ podstawowymi systemami periodyzacji i datowania wyróżnianych okresów. Ostatnio nowsze propozycje datowania i zsynchronizowania systemów periodyzacyjnych kilku polskich Autorów, trochę obciążonych mniejszym lub większym stopniem intuicji badawczej, zestawił T. Purowski (2019, 11-13).

Dokonując przeglądu przytoczonych przykładów, uzmysławiamy sobie, że znajdujemy w nich duże rozbieżności w podawaniu dat bezwzględnych dla poszczególnych wyróżnianych okresów. Podobnie również w przypadku systemów periodyzacyjnych wyróżniających okresy, jak to jest w klasycznych propozycjach O. Monteliusa i P. Reineckiego, mamy także duży wachlarz proponowanych modyfikacji przez różnych badaczy dla poszczególnych regionów Europy, stosujących różną terminologię, jak fazy, etapy itp. Przeważnie nawiązują jednak do wspomnianych dwóch klasycznych. Doskonałą ilustrację tej rozmaitości publikują ostatnio V. Furmánek i V. Mitáš (2016). W stosunku do terenów nas $\mathrm{w}$ tym przypadku interesujących, a mianowicie Śląska, porównawcze zestawienie tabelaryczne ilustrujące datowania poszczególnych okresów, jak też próbę wyróżniania faz i etapów przemian kulturowych dokonujących się w okresie wyróżnianej kultury łużyckiej, znajdujemy we wspomnianej publikacji B. Gedigi (1982, tab. 1).

Ogólnie, po przeglądzie przypomnianych kilku systemów, można powiedzieć, że różnice $\mathrm{w}$ datowaniu poszczególnych okresów wahają się między

1 EB oznacza epoka brązu dla systemu wg O. Monteliusa
50 a 100 lat. Wynikały one z prób dokonywania korekt w odniesieniu do ziem polskich, zakładających pewne opóźnienia np. w stosunku do kręgu nordyjskiego, południowego czy halsztackiego, szacowane dość schematycznie. Ilustracją tego może być choćby kilka wybranych przykładów obejmujących czas łużyckich pól popielnicowych, poczynając od starszej epoki brązu po wczesny okres lateński, tzn. od około 1400 do około III w. p.n.e.

W przypadku wspomnianych propozycji G. Jacoba-Friesena (1973, 644-645) i B. Gedigi (1982, tab. 1) początki kształtowania się kultur pól popielnicowych, w tym także kultury łużyckiej, to czas obejmujący już lata między 1400 a 1300 p.n.e., co oznacza okres $\mathrm{BC}^{2}$ wg systemu P. Reineckiego, i częściej od około 1300 do 1200 p.n.e., a więc to okresy BD oraz III EB (1250-1100 p.n.e.) - okres epoki brązu w systemie północnym $\mathrm{O}$. Monteliusa. W ujęciu J. Kostrzewskiego dla ziem polskich to czas od około 1200 p.n.e., a więc III (EB) okres epoki brązu (1200-1000 p.n.e.), co przypada już na okres HA (1200-1000 p.n.e.) w systemie P. Reineckiego. We wspomnianym wyżej opracowaniu A. Gardawskiego okres BD to krótki czas między 1250 a 1200 i pokrywa się z końcową fazą II EB według J. Kostrzewskiego i obejmuje początki III EB wg systemu północnego O. Monteliusa. Jan Dąbrowski w podawanym przez siebie schemacie ukazującym system O. Monteliusa, P. Reineckiego i J. Kostrzewskiego podaje trochę inne daty bezwzględne, co stanowi kolejne potwierdzenie różnorodności, o której wspomniano wyżej. W tej wersji środkowy III EB okres epoki brązu wg J. Kostrzewskiego miałby się rozpoczynać inaczej niż to jest u tego Badacza $(1965,143)$, bo w 1250 r. p.n.e. i sięgać po 1050 r. p.n.e., pokrywałby się z datowaniem według O. Monteliusa i przypadał na część okresu BD i część HA według P. Reineckiego. Ta propozycja różni się też od wspomnianego opracowania A. Gardawskiego, w którego ujęciu III EB to czas od 1200 do 1000 r. p.n.e. jak u J. Kostrzewskiego, a co różni się od dat wyznaczanych temu okresowi w systemie O. Monteliusa, jak to podano już wyżej, a przypadałby na BD oraz znaczną część okresu HA w systemie południowym. Te rozbieżności w datowaniu poszczególnych okresów istnieją również w odniesieniu do młodszych okresów, przy

2 BD, HA, HB, HC, HD oznaczają skróty okresów epoki brązu i wczesnej epoki żelaza w systemie południowym P. Reineckiego 
czym w przypadku IV EB ta rozbieżność między systemem O. Monteliusa a J. Kostrzewskiego sięga stu lat. Pozostawiając szczegółową analizę tych rozbieżności, ukazanych m.in. na tablicach $\mathrm{w}$ publikacji B. Gedigi (1982, Tab. 1), G. Jacoba-Friesena (1973, 644-645), A. Gardawskiego (Dąbrowski, Rajewski - red. 1979, 24) i J. Dąbrowskiego (2009, 17, Tab. 1) i innych wyżej wspomnianych, kilka słów komentarza poświęcimy jeszcze datowaniu okresu wczesnej epoki żelaza, ważnego dla stanowiska w Domasławiu.

Początki tej nowej epoki żelaza, której najstarszy okres jest określany jako halsztacki, sytuowane są na rok 700 p.n.e., a nawet jako ,wczesny Hallstatt" na 750 p.n.e. (Jacob-Friesen 1973, 644; Gediga 1982, Tab.1). W kręgu północnym-nordyjskim mamy dalsze trwanie epoki brązu jako okres VI EB. Dla terenu ziem polskich J. Kostrzewski wyznacza początki okresu halsztackiego na 650 rok p.n.e., uwzględniając pewne opóźnienie w napływie oddziaływań z kręgu halsztackiego oceniane trochę schematycznie, ale też nie ma większych możliwości, by postąpić inaczej. Koncepcja J. Kostrzewskiego została przyjęta przez A. Gardawskiego oraz J. Dąbrowskiego, przy czym wyznaczają oni podobne ramy czasowe dla okresu halsztackiego HC w systemie P. Reineckiego, co już nie jest całkiem poprawne (por. Jacob-Friesen 1973, 644).

Po przypomnieniu i częściowym skomentowaniu dotychczasowych najważniejszych archeologicznych systemów periodyzacji i datowania wyróżnianych okresów epoki brązu i wczesnej epoki żelaza rodzi się pytanie, jak ustosunkowywać się do uzyskiwanych datowań radiowęglowych, choćby posługując się tylko większymi seriami, jakie mamy obecnie ze stanowiska w Kietrzu na Górnym Śląsku i z Domasławia na Dolnym Śląsku. W obu tych regionach obserwujemy w tym czasie analogiczny rytm przemian kulturowych.

W dużej mierze uzyskujemy szczegółową ocenę i interpretację otrzymanych dat $\mathrm{w}$ artykule pióra Profesora Tomasza Goslara (w tym tomie). Istotnym zagadnieniem staje się wobec przybywania dat bezwzględnych w rezultacie analiz radiowęglowych ustosunkowanie się do tych wyników samych archeologów i wykorzystywania ich do uściślania i poprawiania periodyzacji oraz chronologii poszczególnych etapów pradziejów. W naszym konkretnym przypadku, jak już to zostało przypomniane, poczynając od środkowej epoki brązu po początki następnej epoki żelaza to czas znacznego osłabienia kontaktów z kręgiem cywilizacji śródziemnomorskiej, przypadający na tzw. wieki ciemne (Krawczuk 2000, 112). Jest to jednoznaczne z utratą lepszych przesłanek do datowań bezwzględnych, jakie stwarza chronologia choćby kręgu cywilizacji egejskiej. Dotychczasowe podziały wykorzystywały i nadal wykorzystują głównie metody klasyfikacji typologicznej (por. szczegółowe, znakomite omówienie $\mathrm{i}$ analizę klasyfikacji $\mathrm{w}$ archeologii Minta-Tworzowska 1994) przy porządkowaniu odkrywanych podczas badań faktów w postaci m.in. obiektów stałych, jak też przede wszystkim zabytków ruchomych. To postępowanie obarcza relatywnie mała wartość intersubiektywności, niemniej tym sposobem skonstruowane zostały m.in. podstawowe systemy periodyzacji epoki brązu i żelaza. Również w przypadku cmentarzyska w Domasławiu głównie stylistyczne przemiany przedmiotów stanowiących wyposażenie grobów i ich porównania $\mathrm{z}$ dotychczasowymi kryteriami periodyzacji legły u podstaw porównania oraz zsynchronizowania tak konstruowanej periodyzacji z datami uzyskanymi w wyniku analiz radiowęglowych. Przed takim zadaniem stawać będziemy coraz częściej, w miarę postępu badań na tym polu i będziemy zaskakiwani wynikami niedającymi się łatwo zsynchronizować z dotychczasową periodyzacją i chronologią czasu pradziejów. Temu problemowi w naszym konkretnym przypadku wypada, biorąc pod uwagę znaczną ilość uzyskanych dat, poświęcić parę słów uwagi.

Generalnie, zestawiając wyniki badań radiowęglowych $\mathrm{z}$ dotychczasowym datowaniem poszczególnych okresów epoki brązu i wczesnej epoki żelaza, można powiedzieć, że w zdecydowanej większości pozyskane daty mieszczą się w jakichś częściach przedziałów czasowych wyznaczanych dla owych okresów i ukazują prawidłowo następstwo czasowe ustalone na podstawie analiz stylistycznych. Podobny wniosek dało się sformułować w odniesieniu do wyników badań próbek z grobów kietrzańskich (Chochorowski 2007, 130-132). Otrzymane daty obejmują szersze przedziały czasowe, a zdajemy sobie sprawę z tego, że każdy z grobów, z którego próbka była przedmiotem analizy, był $\mathrm{w}$ gruncie rzeczy wydarzeniem jednorazowym lub w bliskim czasie. Jak widzimy jednak w przypadku cmentarzyska w Kietrzu, gdy przedmiotem badań były próbki pobierane $\mathrm{z}$ różnej głębokości tego samego obiektu, daty są różne, choć ogólnie w mniejszym lub większym stopniu zbieżne (Chochorowski 2007, 134-137, Zestawienie 1, 2). 
Analizując wyniki zestawione poniżej w Tabeli 1 sporządzonej przez Profesora T. Goslara i biorąc pod uwage pełny ich wachlarz dla każdego obiek- tu, zarówno zestawione $\mathrm{w}$ różnych procentowych wartościach kalibracji, jak też zestawione w dwóch modelach A i B, niektóre rodzą następujące uwagi.

Tabela 1. Wyniki datowania ${ }^{14} \mathrm{C}$ próbek kości ze stanowiska w Domasławiu. Podane są $68 \%$ i 95\% przedziały ufności dat kalibrowanych pojedynczych próbek oraz przedziały ufności dat obliczonych modelowo (Model B)

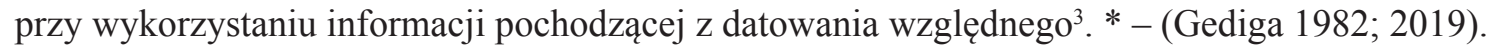

Table 1. Results of ${ }^{14} \mathrm{C}$ dating of bone samples from the site in Domasław. The $68 \%$ and $95 \%$ confidence intervals of calibrated dates of individual samples are given, as well as the confidence intervals of dates calculated by model (Model B) using information from relative dating ${ }^{3}{ }^{*}$ - (Gediga 1982; 2019).

\begin{tabular}{|c|c|c|c|c|c|c|c|}
\hline $\begin{array}{l}\text { Nr grobu } \\
\text { No. of } \\
\text { grave }\end{array}$ & $\begin{array}{c}\text { Nr lab. } \\
\text { No. of lab. }\end{array}$ & $\begin{array}{c}\text { Wiek } \\
{ }^{14} \mathrm{C} \text { BP } \\
\text { Date } \\
{ }^{14} \mathrm{C} \mathrm{BP}\end{array}$ & $\begin{array}{c}\text { Data } \\
\text { kalibrowana } \\
\text { BC (68,2\%) } \\
\text { Calibrated } \\
\text { date BC } \\
(68,2 \%)\end{array}$ & $\begin{array}{c}\text { Data } \\
\text { kalibrowana } \\
\text { BC (95,4\%) } \\
\text { Calibrated } \\
\text { date BC } \\
(95,4 \%)\end{array}$ & $\begin{array}{l}\text { Datowanie } \\
\text { względne } \\
\text { zespołu wg } \\
\text { B. Gedigi* } \\
\text { Relative } \\
\text { dating of } \\
\text { assemblage } \\
\text { after } \\
\text { B. Gediga* }\end{array}$ & $\begin{array}{c}\text { Data } \\
\text { w Modelu B } \\
\text { BC }(\mathbf{6 8}, \mathbf{2 \%}) \\
\text { Date in } \\
\text { Model B } \\
\text { BC }(68,2 \%)\end{array}$ & $\begin{array}{c}\text { Data } \\
\text { w Modelu B } \\
\text { BC }(\mathbf{9 5}, \mathbf{4 \%} \%) \\
\text { Date in } \\
\text { Model B } \\
\text { BC }(95,4 \%)\end{array}$ \\
\hline 10336 & Poz-96690 & $2285 \pm 30$ & $399-262$ & $405-213$ & LtA & $400-378$ & $405-362$ \\
\hline 8966 & Poz-96457 & $2455 \pm 30$ & $749-485$ & $756-413$ & HD & $549-428$ & $575-409$ \\
\hline 8893 & Poz-85730 & $2465 \pm 30$ & $751-516$ & $764-430$ & $\mathrm{HC} / \mathrm{HD}$ & $735-490$ & $751-428$ \\
\hline 4417 & Poz-85723 & $2430 \pm 30$ & $727-414$ & $750-405$ & $\mathrm{HC} / \mathrm{HD}$ & $541-415$ & $744-404$ \\
\hline 12117 & Poz-85666 & $2540 \pm 30$ & $795-591$ & $799-547$ & $\mathrm{HC}$ & $797-600$ & $801-555$ \\
\hline 10821 & Poz-85663 & $2675 \pm 30$ & $887-803$ & $896-800$ & $\mathrm{HC}$ & $831-806$ & 856-796 \\
\hline 8956 & Poz-85732 & $2570 \pm 30$ & $802-766$ & $809-559$ & $\mathrm{HC}$ & $802-766$ & $810-561$ \\
\hline 8905 & Poz-85731 & $2545 \pm 30$ & $797-592$ & $801-549$ & $\mathrm{HC}$ & $797-591$ & $801-549$ \\
\hline 4271 & Poz-85722 & $2545 \pm 30$ & $797-592$ & $801-549$ & $\mathrm{HC}$ & $797-592$ & $801-550$ \\
\hline 4270 & Poz- 85720 & $2500 \pm 30$ & $767-552$ & $788-537$ & $\mathrm{HC}$ & $767-558$ & $779-541$ \\
\hline 1693 & Poz-85716 & $2605 \pm 30$ & $810-786$ & $825-768$ & $\mathrm{HC}$ & $809-786$ & $824-768$ \\
\hline 818 & Poz-85715 & $2495 \pm 30$ & $763-550$ & $783-517$ & $\mathrm{HC}$ & $763-556$ & $776-539$ \\
\hline 390 & Poz-85714 & $2565 \pm 30$ & $802-761$ & $806-556$ & $\mathrm{HC}$ & $802-761$ & $808-556$ \\
\hline 369 & Poz-85713 & $2500 \pm 30$ & $767-552$ & $788-537$ & $\mathrm{HC}$ & $767-556$ & $780-541$ \\
\hline 366 & Poz-85712 & $2560 \pm 30$ & $801-599$ & $805-553$ & $\mathrm{HC}$ & $801-599$ & $806-556$ \\
\hline F 77 & Poz-92820 & $2775 \pm 35$ & $976-850$ & $1005-836$ & $\mathrm{VEB} / \mathrm{HC}$ & $973-855$ & $990-839$ \\
\hline F 213 & Poz-92816 & $2815 \pm 35$ & $1007-922$ & $1073-850$ & VEB & $981-916$ & $1010-856$ \\
\hline E 233 & Poz-92821 & $2815 \pm 35$ & $1007-922$ & $1073-850$ & VEB & $981-916$ & $1010-854$ \\
\hline B 225 & Poz-92855 & $2725 \pm 30$ & $897-836$ & $924-812$ & VEB & $900-840$ & $924-820$ \\
\hline В 106 & Poz-92861 & $2810 \pm 30$ & $1000-925$ & $1050-895$ & VEB & $978-918$ & $1009-895$ \\
\hline 3496 & Poz-85719 & $2725 \pm 30$ & $897-836$ & $924-812$ & VEB & $900-840$ & $925-820$ \\
\hline
\end{tabular}




\begin{tabular}{|c|c|c|c|c|c|c|c|}
\hline C 195 & Poz-92850 & $2935 \pm 35$ & $1210-1060$ & 1257-1019 & IV/VEB & $1210-1085$ & $1231-1018$ \\
\hline В 116 & Poz-92858 & $2870 \pm 30$ & $1110-1003$ & $1127-931$ & IV/VEB & $1107-1005$ & $1187-973$ \\
\hline F 212 & Poz-92817 & $2865 \pm 35$ & $1110-981$ & $1188-923$ & IV/VEB & $1110-994$ & $1187-923$ \\
\hline C 95 & Poz-92852 & $2940 \pm 30$ & 1213-1111 & $1257-1044$ & IV/VEB & $1213-1110$ & $1232-1039$ \\
\hline В 144 & Poz-92856 & $2950 \pm 35$ & $1223-1112$ & 1264-1044 & IV/VEB & $1222-1112$ & $1261-1048$ \\
\hline 12012 & Poz- 85665 & $2825 \pm 30$ & $1011-929$ & $1071-902$ & IV/VEB & $1011-930$ & $1075-902$ \\
\hline 10140 & Poz-85733 & $2800 \pm 30$ & $996-915$ & $1027-848$ & IV/VEB & $994-915$ & $1026-849$ \\
\hline F 197 & Poz-92819 & $2930 \pm 35$ & 1196-1057 & $1226-1014$ & IVEB & 1196-1060 & $1225-1016$ \\
\hline E 83 & Poz-92823 & $3065 \pm 35$ & $1393-1280$ & $1415-1230$ & IVEB & $1292-1229$ & $1319-1206$ \\
\hline C 200 & Poz-92849 & $2925 \pm 30$ & $1192-1056$ & 1215-1022 & IVEB & $1192-1057$ & $1215-1023$ \\
\hline C 97 & Poz-92851 & $2855 \pm 30$ & $1056-940$ & $1115-928$ & IVEB & $1070-985$ & $1121-968$ \\
\hline C 19 & Poz-92854 & $2865 \pm 30$ & $1109-996$ & $1123-930$ & IVEB & 1109-996 & $1123-930$ \\
\hline 8428 & Poz-85726 & $2835 \pm 30$ & 1023-931 & $1107-911$ & IVEB & $1025-931$ & 1086-911 \\
\hline 8375 & Poz- 85725 & $2835 \pm 30$ & $1023-931$ & $1107-911$ & IVEB & $1024-931$ & $1107-911$ \\
\hline B 85 & Poz-92862 & $2825 \pm 30$ & $1011-929$ & $1071-902$ & IVEB & $1039-975$ & $1107-949$ \\
\hline 5011 & Poz-85724 & $2840 \pm 30$ & $1043-936$ & $1108-917$ & IVEB & $1049-981$ & $1112-963$ \\
\hline F 222 & Poz-92815 & $3040 \pm 35$ & 1384-1231 & $1410-1208$ & III/IVEB & $1283-1224$ & $1310-1131$ \\
\hline В 110 & Poz-92859 & $3040 \pm 35$ & 1384-1231 & $1410-1208$ & III/IVEB & $1284-1225$ & $1310-1131$ \\
\hline E 110 & Poz-92822 & $3280 \pm 40$ & $1611-1516$ & $1658-1453$ & IIIEB & $1515-1434$ & $1547-1420$ \\
\hline Е 27 & Poz-92824 & $3170 \pm 30$ & $1495-1416$ & 1505-1396 & IIIEB & $1463-1412$ & $1500-1395$ \\
\hline D 11 & Poz-92848 & $3070 \pm 35$ & 1394-1285 & 1419-1231 & IIIEB & 1394-1298 & $1416-1274$ \\
\hline C 162 & Poz-93156 & $3090 \pm 40$ & $1413-1298$ & $1437-1233$ & IIIEB & $1411-1303$ & $1432-1278$ \\
\hline В 109 & Poz-92860 & $3095 \pm 35$ & 1414-1302 & $1432-1267$ & IIIEB & $1413-1306$ & $1431-1284$ \\
\hline В 64 & Poz-92863 & $3070 \pm 30$ & $1393-1287$ & $1415-1236$ & IIIEB & 1392-1299 & $1412-1278$ \\
\hline 10162 & Poz-85735 & $3050 \pm 30$ & $1385-1263$ & $1401-1226$ & IIIEB & $1387-1286$ & $1405-1267$ \\
\hline 8659 & Poz-85729 & $3090 \pm 30$ & $1411-1302$ & $1427-1277$ & IIIEB & $1410-1304$ & $1423-1286$ \\
\hline 2892 & Poz-85718 & $3045 \pm 30$ & $1385-1236$ & 1399-1221 & IIIEB & 1386-1282 & $1401-1266$ \\
\hline 2835 & Poz-85717 & $3035 \pm 30$ & $1377-1231$ & 1397-1211 & IIIEB & $1384-1278$ & $1398-1261$ \\
\hline E 220 & Poz-92864 & $3045 \pm 35$ & $1385-1235$ & 1409-1214 & II/IIIEB & $1387-1285$ & $1407-1267$ \\
\hline
\end{tabular}

${ }^{3} \mathrm{Wg}$ T. Goslara w tym tomie. After T. Goslar in this volume.

Najstarszymi obiektami w świetle tych wyników byłyby groby nr E 27 (ryc. 1, 2), E 110 (ryc. 3), B109 (ryc. 4), E 220, 2835, 8659 (ryc. 5). Ustalona klasyfikacja typologiczna (w Tabeli $1 \mathrm{~T}$. Goslara w rubryce wg B. Gedigi) uwzględniająca stylistyczne cechy kontrastuje $\mathrm{z}$ datami radiowęglowymi ustalonymi dla tych obiektów i sytuuje je w dużej mierze w okresie kultur mogiłowych, na ziemiach 

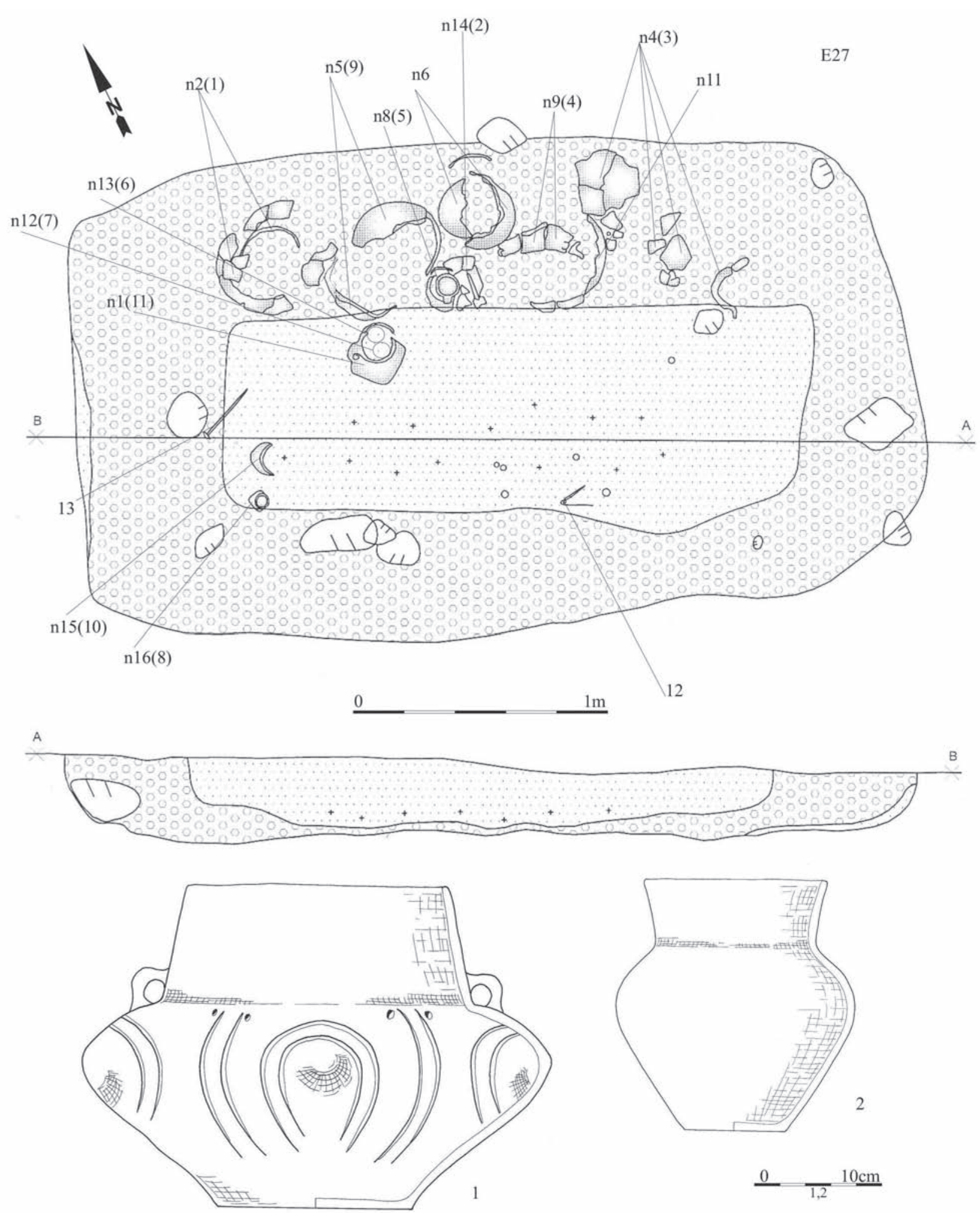

Ryc. 1. Domasław, pow. wrocławski, plan i inwentarz grobu nr E 27. Rys. A Buchner, G. Daszkiewicz i A. Zarzycka Fig. 1. Domasław, Wrocław district, plan and inventory of grave No. E 27. Drawing by. A. Buchner,

G. Daszkiewicz and A. Zarzycka

polskich w wyróżnianej kulturze przedłużyckiej z II EB w periodyzacji O. Montelius/J. Kostrzewski i BC oraz BD w systemie południowym, bardziej właściwym dla obszarów południowo-zachodnich ziem polskich. Do tej klasyfikacji całkowicie przystaje zespół grobowy nr 8659 (ryc. 5), sytuowany tymi datami i cechami inwentarza na czas kultur mogiłowych, jednak reprezentujący już typ grobu 

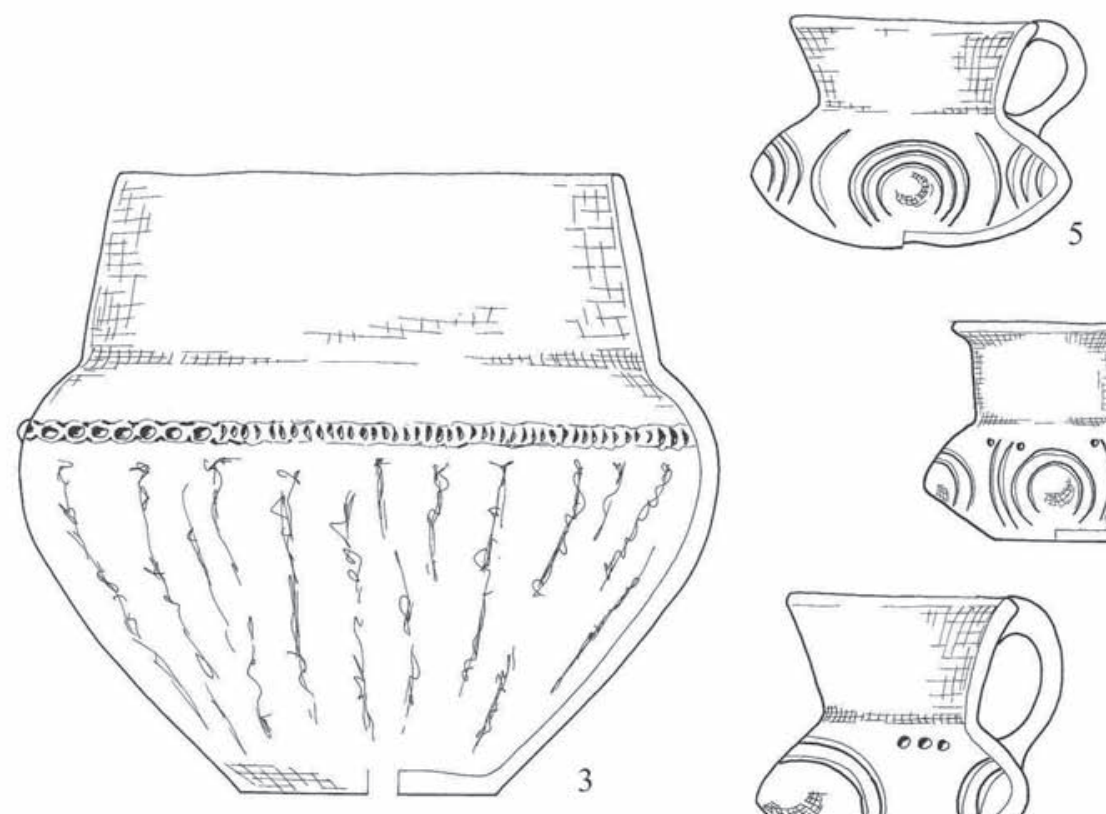

E27
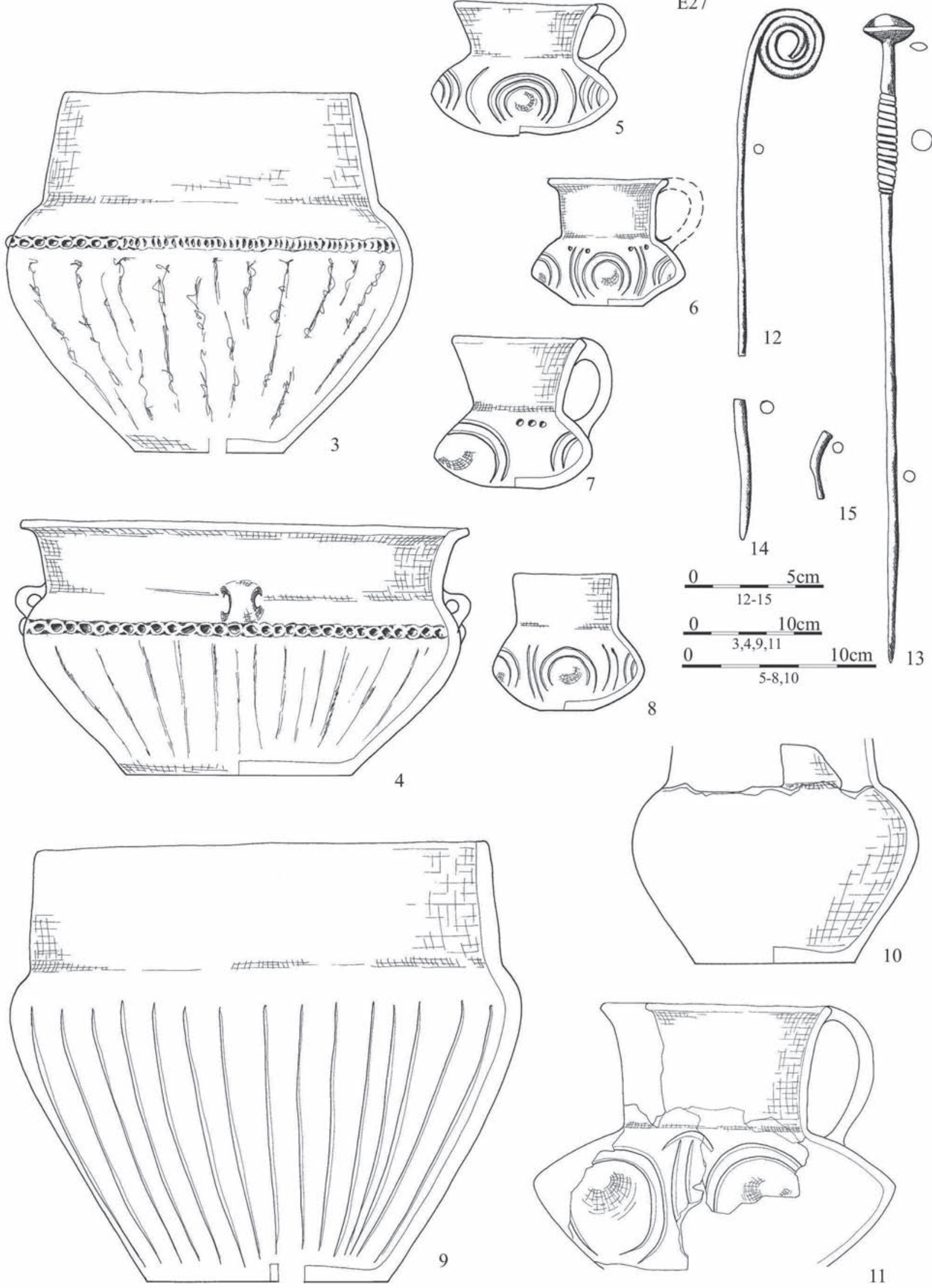

Ryc. 2. Domasław, pow. wrocławski, inwentarz grobu E 27. Rys. A. Zarzycka Fig. 2. Domasław, Wrocław district, inventory of grave No. E 27. Drawing by A. Zarzycka 

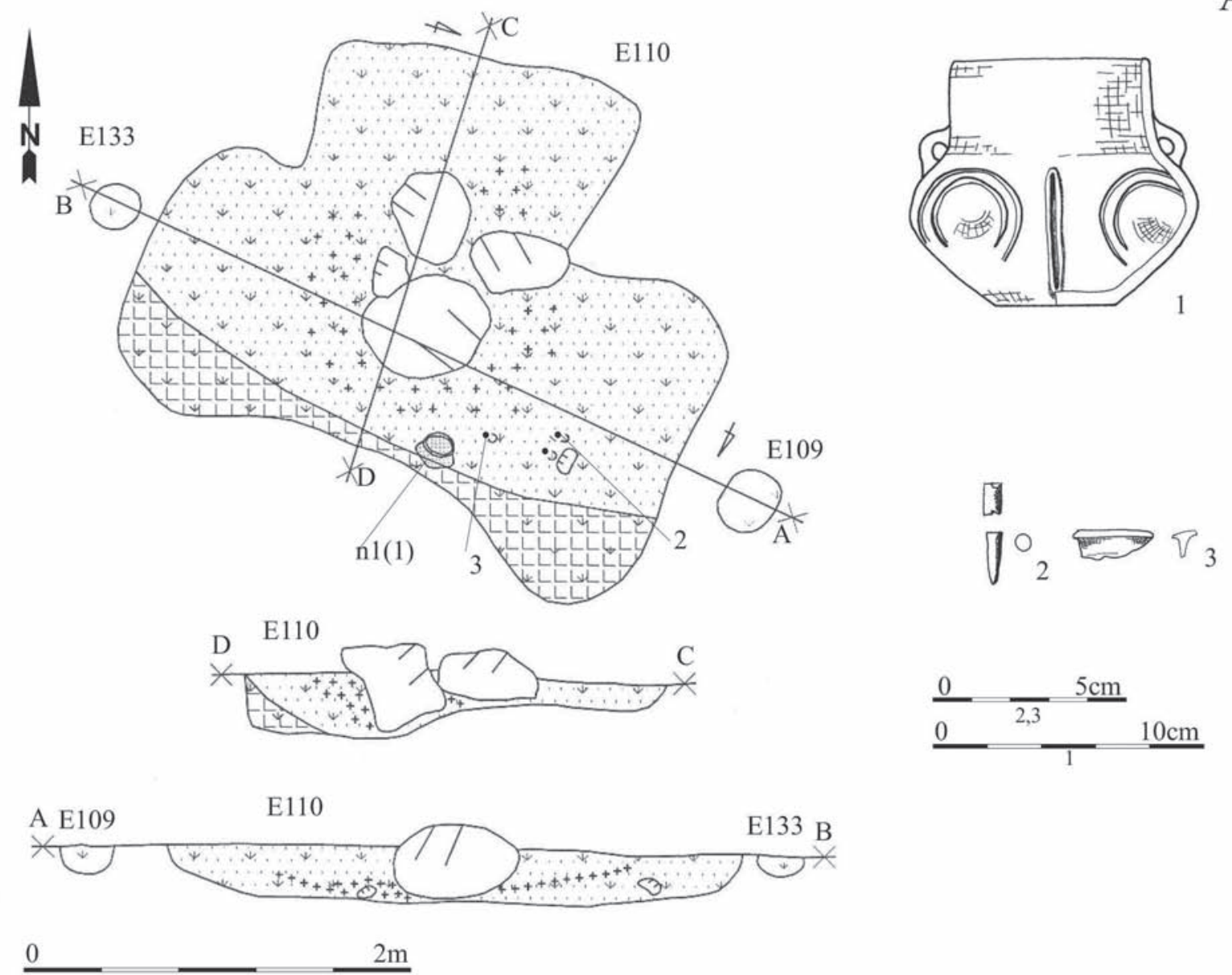

Ryc. 3. Domasław, pow. wrocławski, plan i inwentarz grobu nr E 110. Rys. A. Buchner, G. Daszkiewicz i A. Zarzycka Fig. 3. Domasław, Wrocław district, plan and inventory of grave No. E 110. Drawing by A. Buchner,

G. Daszkiewicz and A. Zarzycka

powszechny w kręgu kultur pól popielnicowych, w tym łużyckiej. Pozostałe wyżej wymienione zespoły grobowe na podstawie analizy typologicznostylistycznej pochodzącego z nich inwentarza, niestety głównie ceramiki, reprezentują już rozwiniętą wczesną fazę okresu rozwoju łużyckich pól popielnicowych z tzw. ceramiką guzową. W tradycyjnym schemacie periodyzacji i chronologii, dokonywanej przy stosowaniu wspomnianych wyżej kryteriów $\mathrm{i}$ analiz porównawczych, jest to, jak wynika z wyżej podanych uwag, na ziemiach polskich, w tym na Śląsku, III EB, czyli środkowy okres epoki brązu, datowany w schemacie O. Montelius/J. Kostrzewski od około $1250 / 1200$ p.n.e. do 1100/1000 p.n.e. W systemie południowym P. Reineckiego to okres BD i HA (Jacob-Friesen 1973, 644; Gediga 1982, Tab. 1). Inaczej trochę te ramy czasowe i sytuowane w nich okresy periodyzacji epoki brązu prezentują A. Gardawski $(1979,24)$ i J. Dąbrowski $(2009$,
Tab. 1). Na czas okresu BD sugeruje się (JacobFriesen 1973,644) pewną równoległość późnych kultur mogiłowych i początków kultur pól popielnicowych, ten etap w przypadku Śląska może mógłby obejmować już okres $\mathrm{BC}_{2}$ (Gediga 1982, Tab. 1), a uzyskane daty radiowęglowe sytuowałyby te zespoły w początkowej fazie kształtowania się łużyckich pól popielnicowych. Ogląd stylistyki inwentarza pochodzącego $\mathrm{z}$ tych obiektów rodzi rozterkę, gdyż tradycyjnie, jak wspomniałem, są to cechy właściwe rozwiniętego wczesnego etapu z ceramiką guzową. Problem ten pozostaje do dalszych rozwiązań w miarę przybywania nowych wyników analiz $\mathrm{C}^{14} \mathrm{i}$ studiów.

Przed prawie analogicznym problemem stajemy w przypadku kilku zespołów grobowych z najmłodszej fazy użytkowania cmentarzyska w Domasławiu z wczesnej epoki żelaza. W świetle przytoczonych powyżej ram czasowych przyjmowanych 


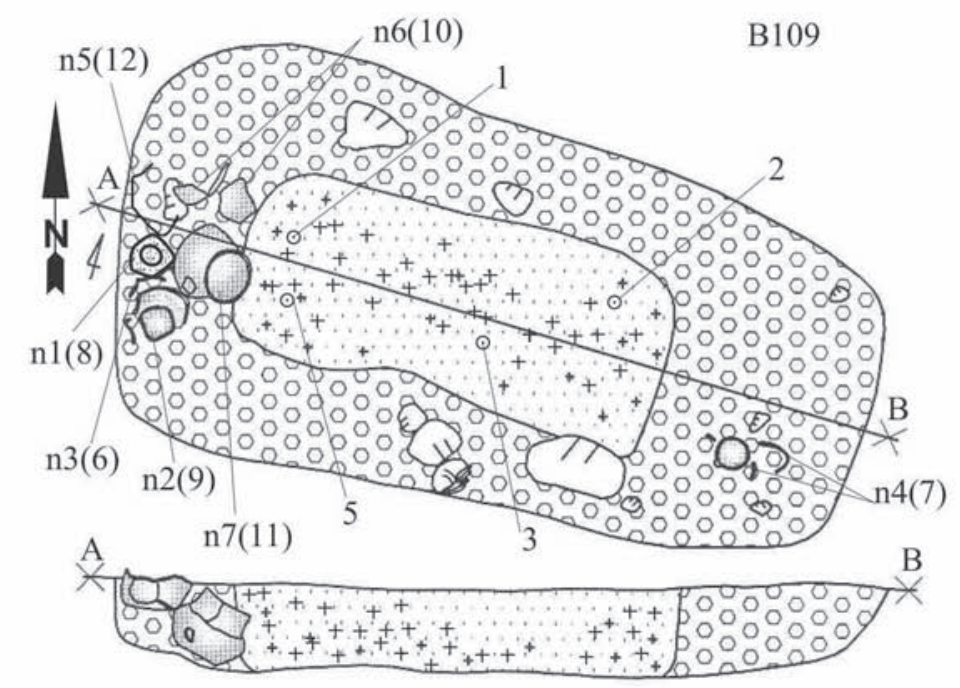

$\underline{0}$ $2 \mathrm{~m}$
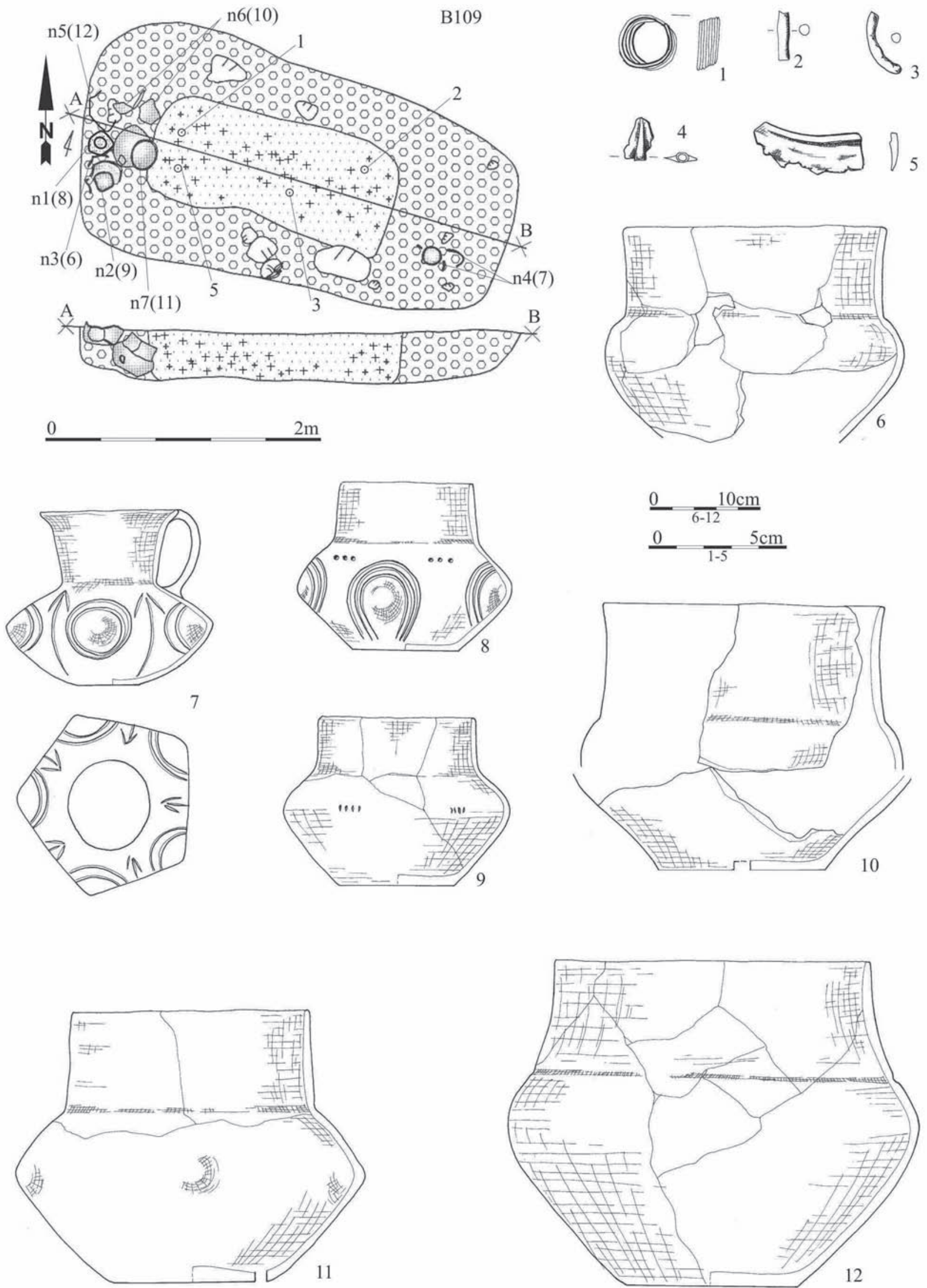

Ryc. 4. Domasław, pow. wrocławski, plan i inwentarz grobu nr B 109. Rys. A Buchner, G. Daszkiewicz i A. Zarzycka Fig. 4. Domasław, Wrocław district, plan and inventory of grave No. B 109. Drawing by A. Buchner,

G. Daszkiewicz and A. Zarzycka 

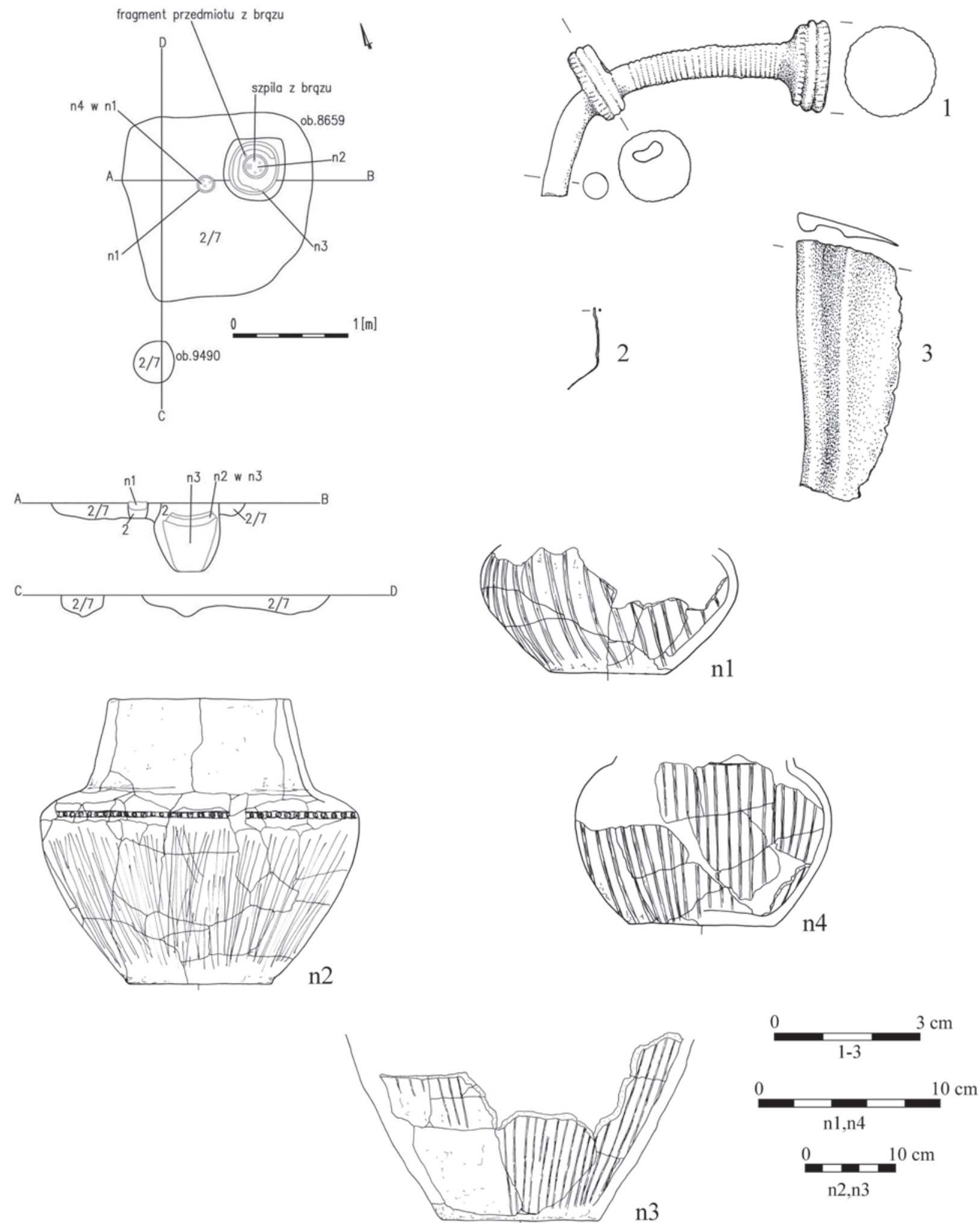

Ryc. 5. Domasław, pow. wrocławski, plan i inwentarz grobu nr E 27. Rys. A. Buchner, G. Daszkiewicz i K. Świątek Fig. 5. Domasław, Wrocław district, plan and inventory of grave No. E 27. Drawing by A. Buchner, G. Daszkiewicz and K. Świątek 

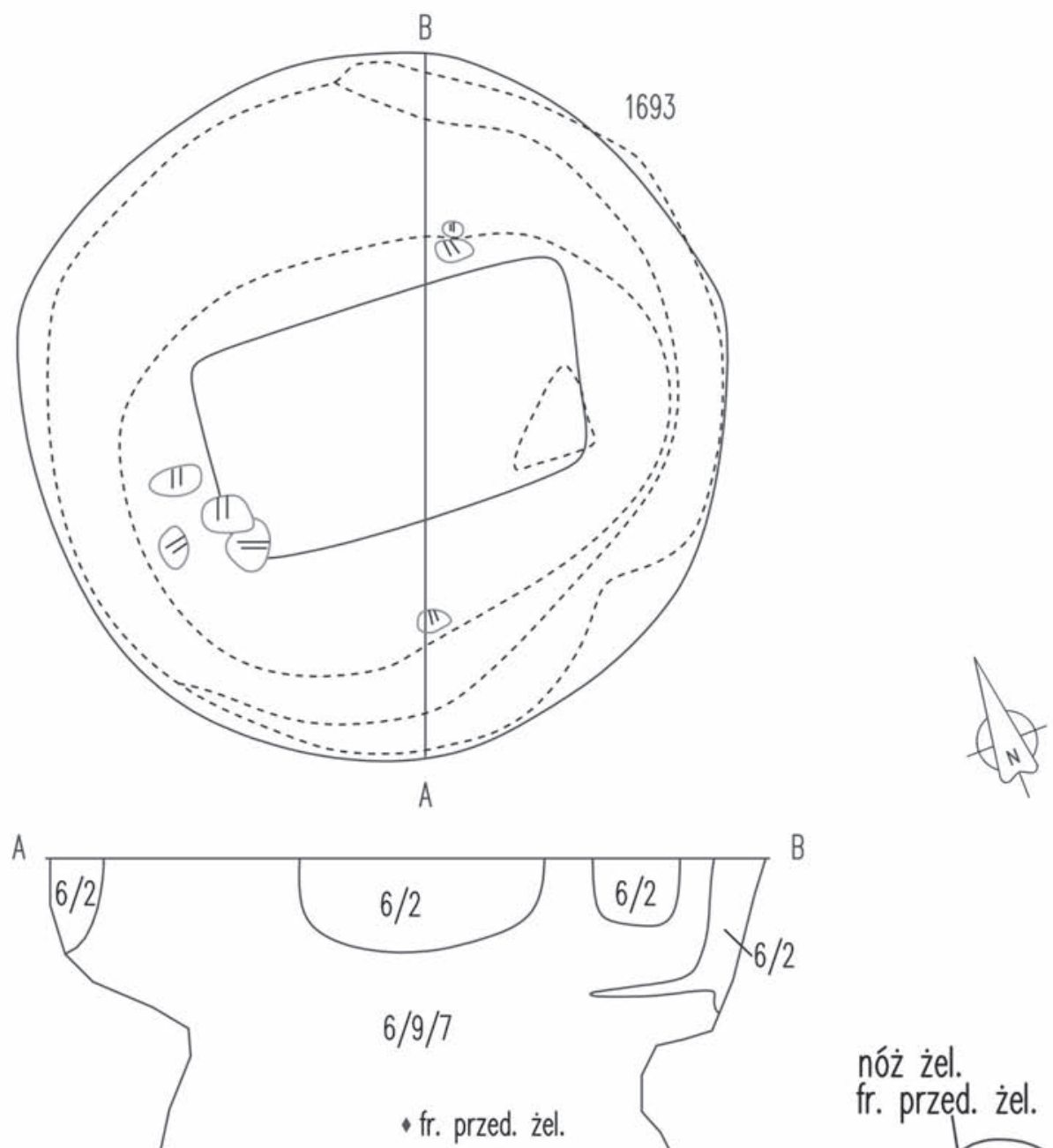

nóż żel.

fr. przed. żel.

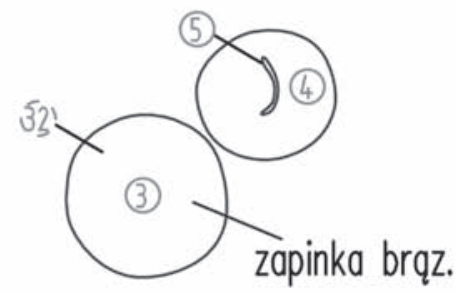

$1[\mathrm{~m}]$
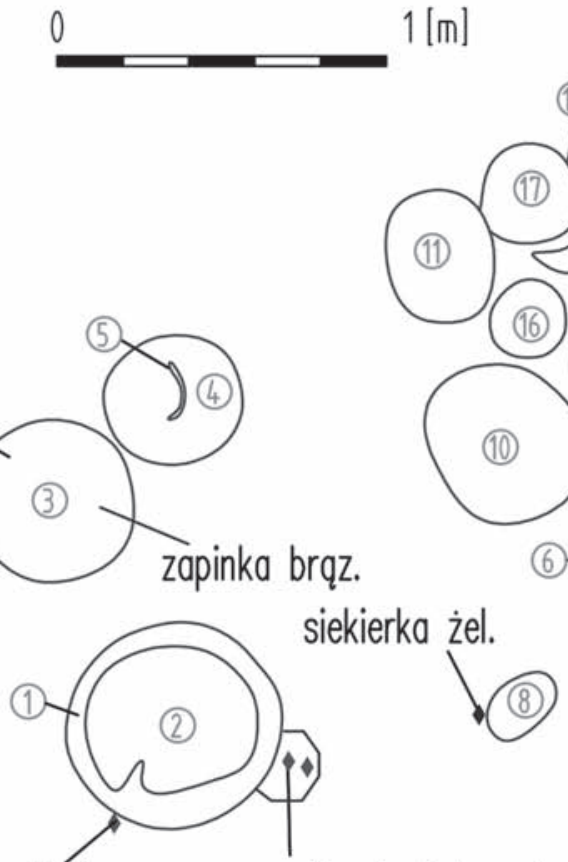

szpila brąz. garnitur toaletowy brąz.

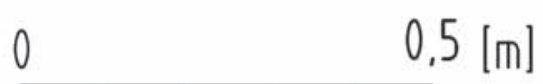

Ryc. 6. Domasław, pow. wrocławski, plan i inwentarz grobu nr 1693. Rys. A Buchner, G. Daszkiewicz i K. Świątek Fig. 6. Domasław, Wrocław district, plan and inventory of grave No. 1693. Drawing by A. Buchner, G. Daszkiewicz and K. Świątek 

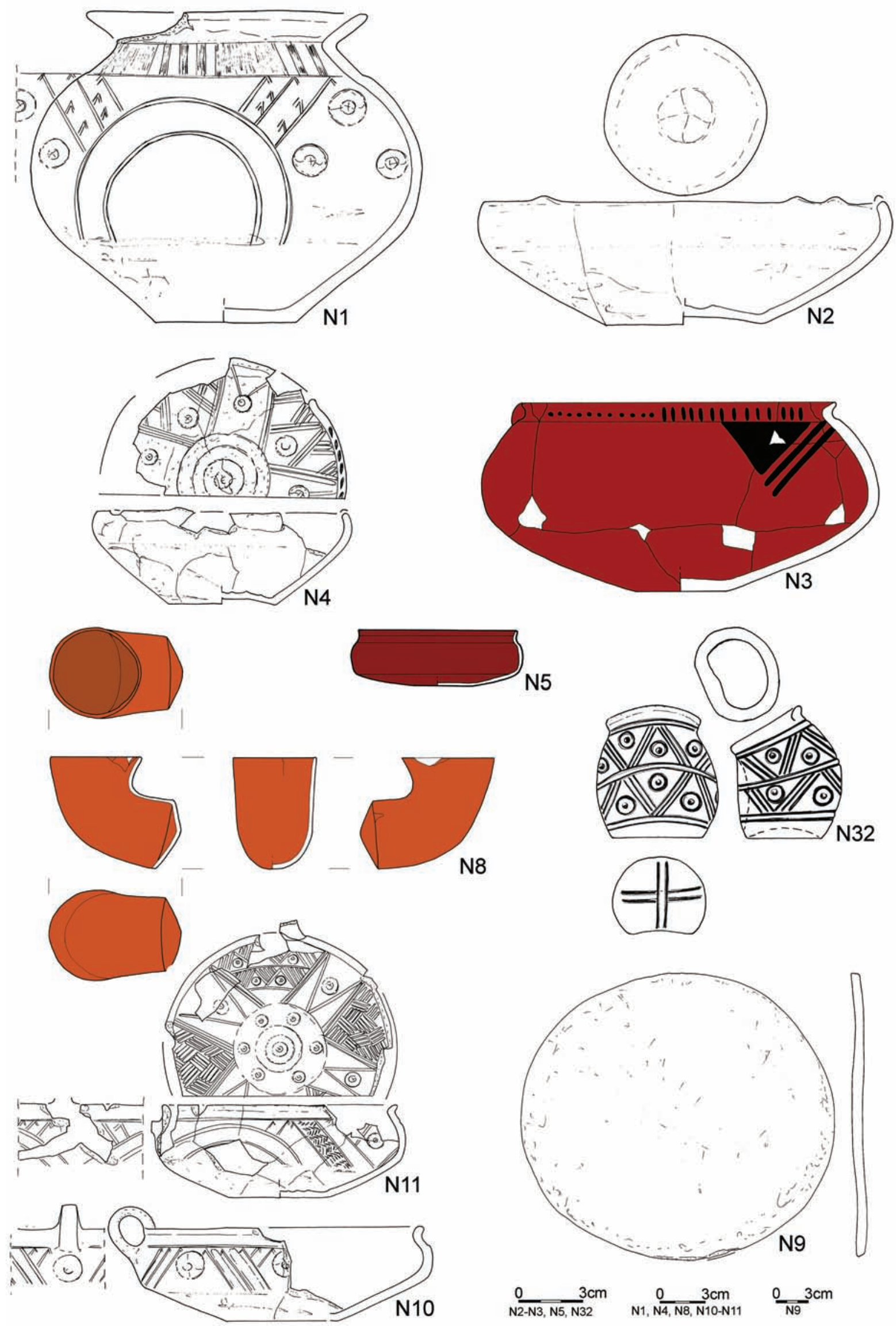

Ryc. 7. Domasław, pow. wrocławski, inwentarz grobu nr 1693. Rys. K. Świątek Fig. 7. Domasław, Wrocław district, inventory of grave No. 1693. Drawing by K. Świątek 

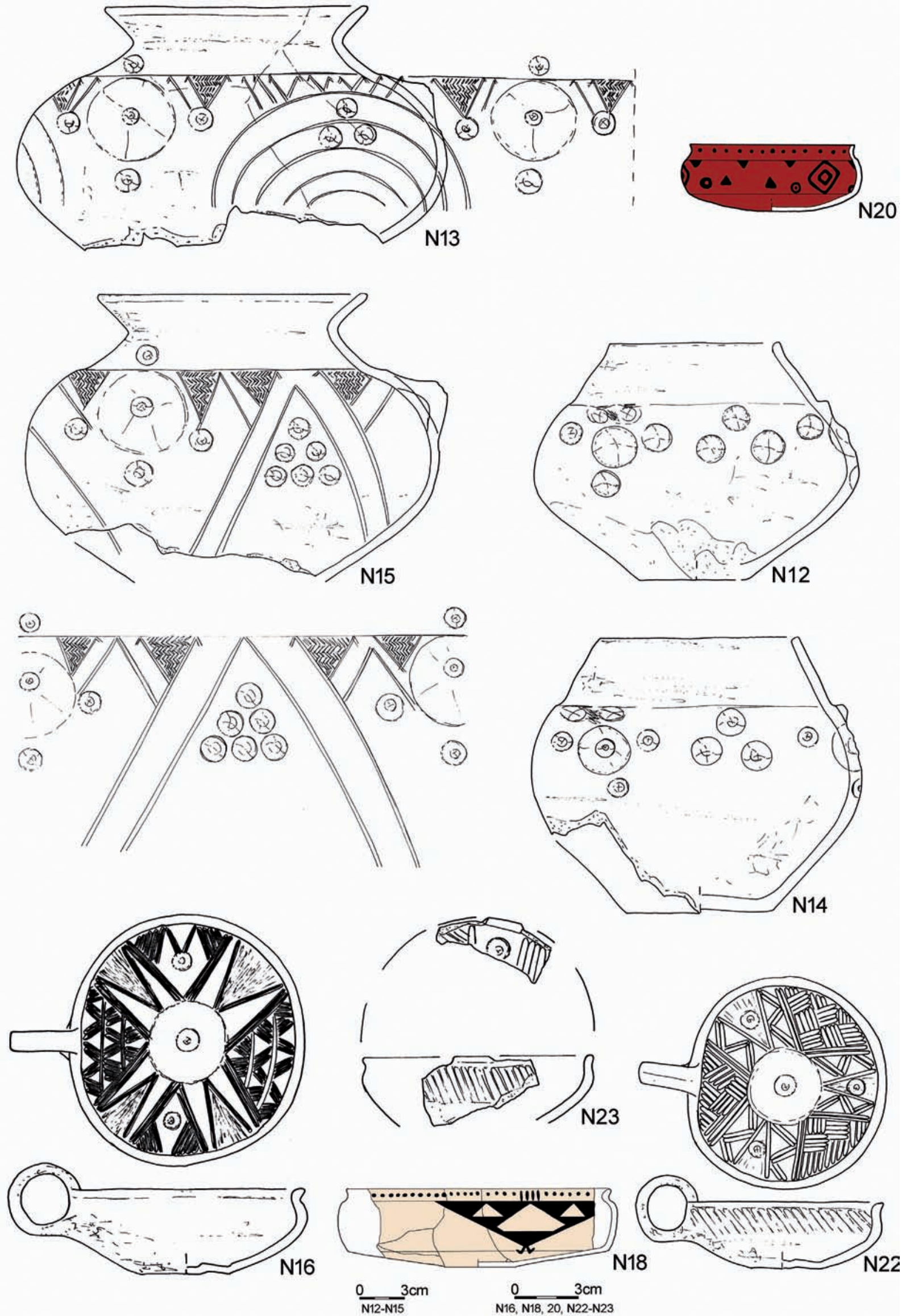

Ryc. 8. Domasław, pow. wrocławski, inwentarz grobu nr 1693. Rys. K. Świątek

Fig. 8. Domasław, Wrocław district, inventory of grave No. 1693. Drawing by K. Świątek 

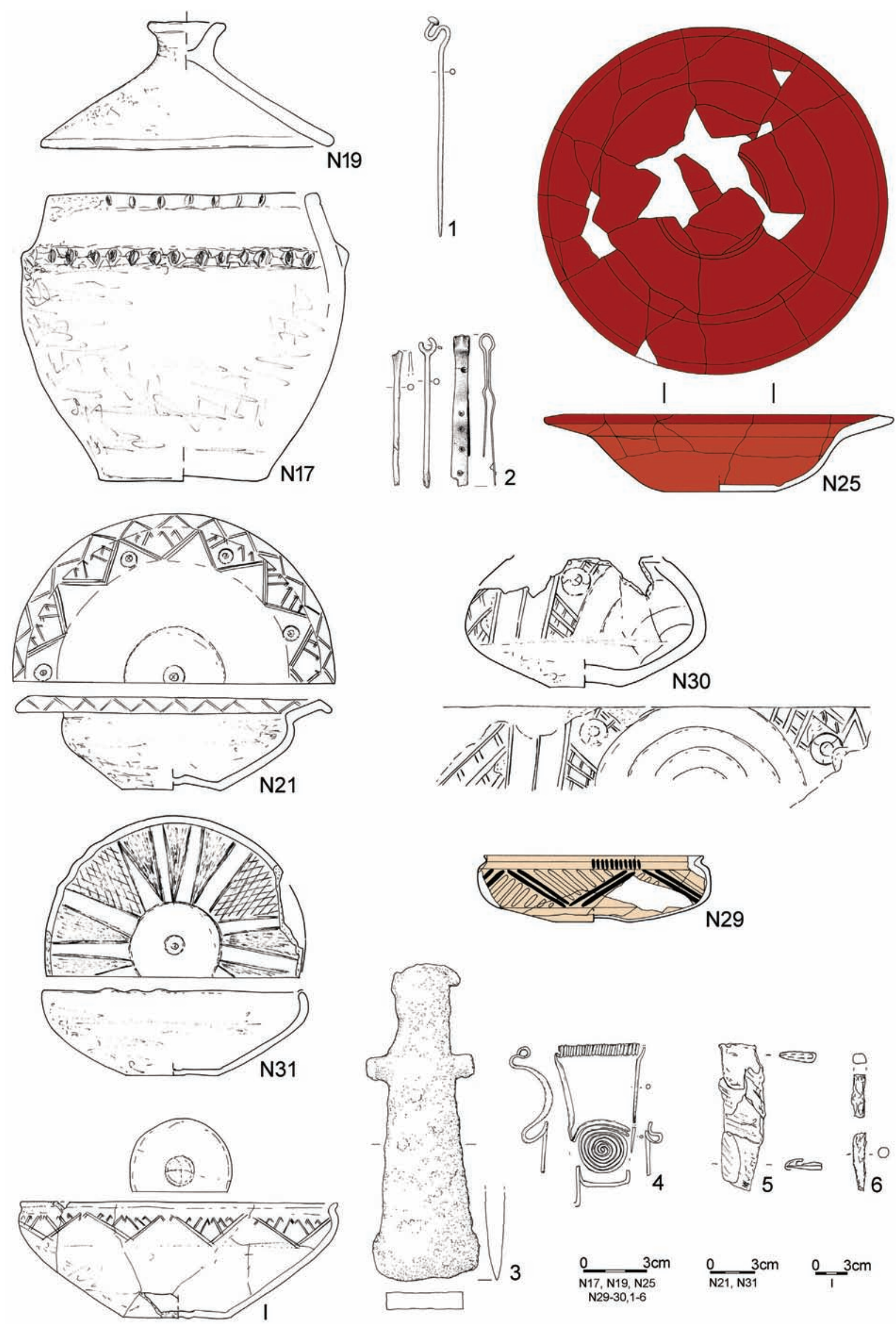

Ryc. 9. Domasław, pow. wrocławski, inwentarz grobu nr 1693. Rys. K. Świątek

Fig. 9. Domasław, Wrocław district, inventory of grave No. 1693. Drawing by K. Świątek 

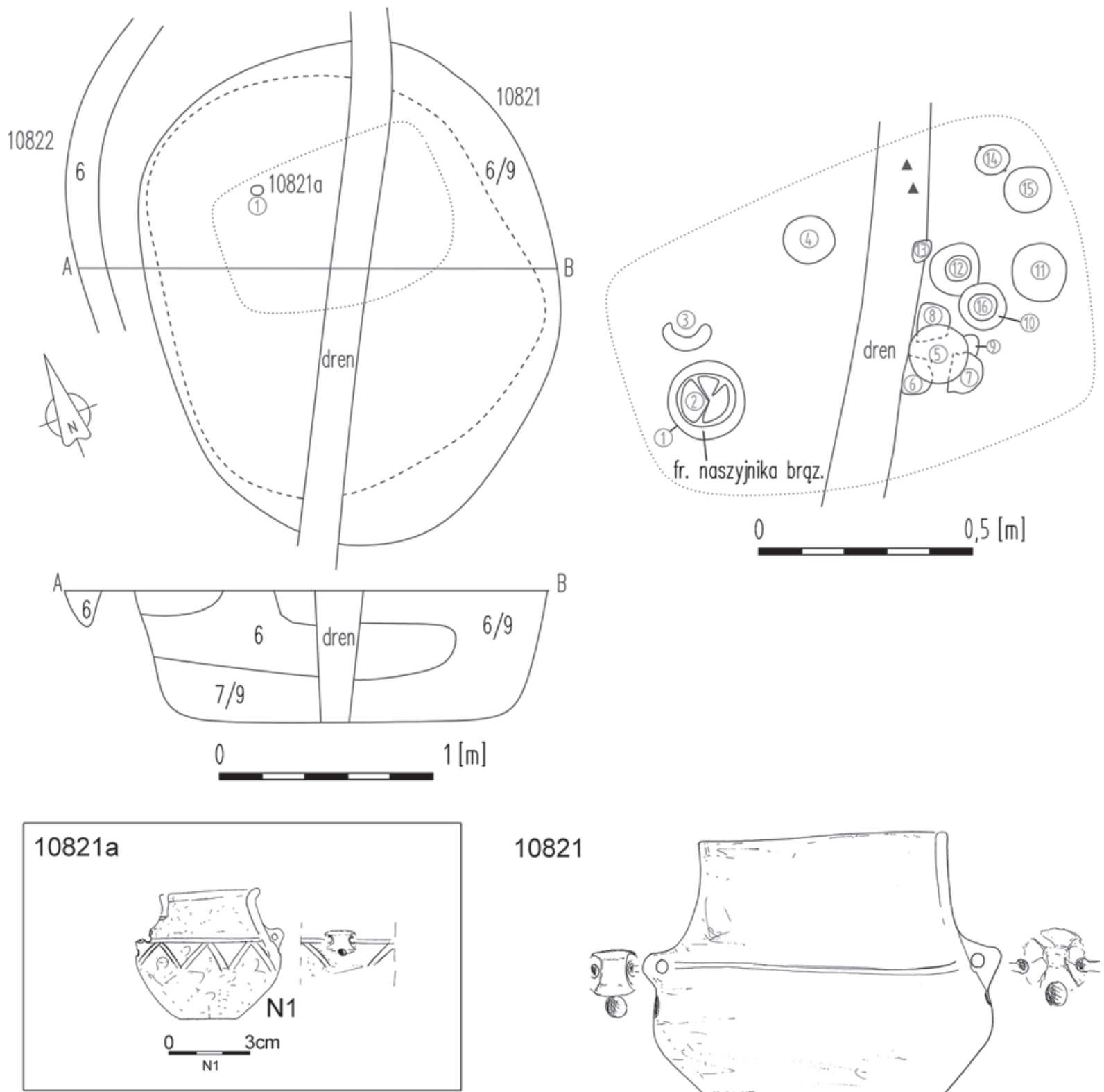

10821
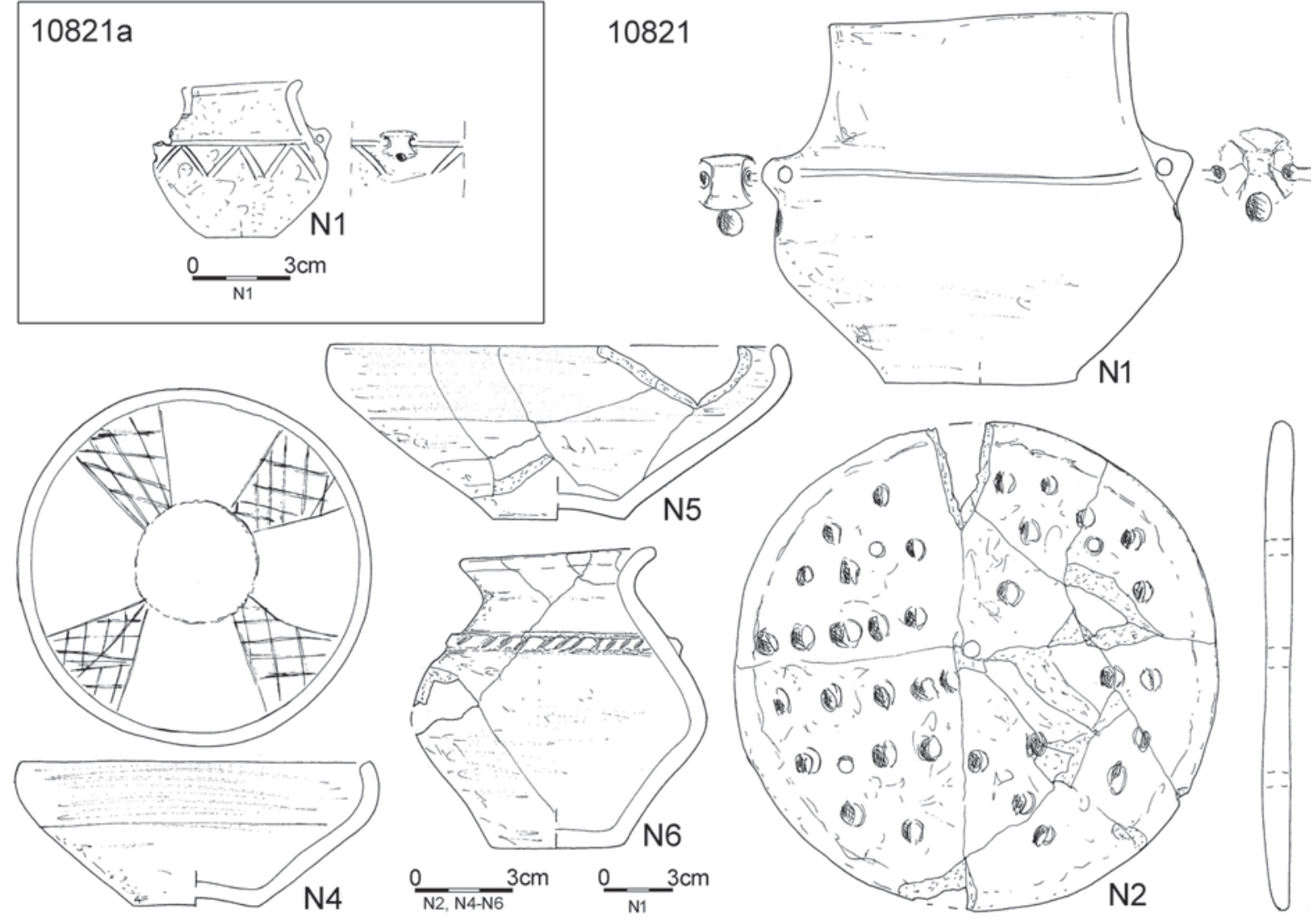

Ryc. 10. Domasław, pow. wrocławski, plan i inwentarz grobu nr 10821. Rys. A. Buchner, G. Daszkiewicz, K. Świątek

Fig. 10. Domasław, Wrocław district, plan and inventory of grave No. 10821. Drawing by A. Buchner,

G. Daszkiewicz and K. Świątek 

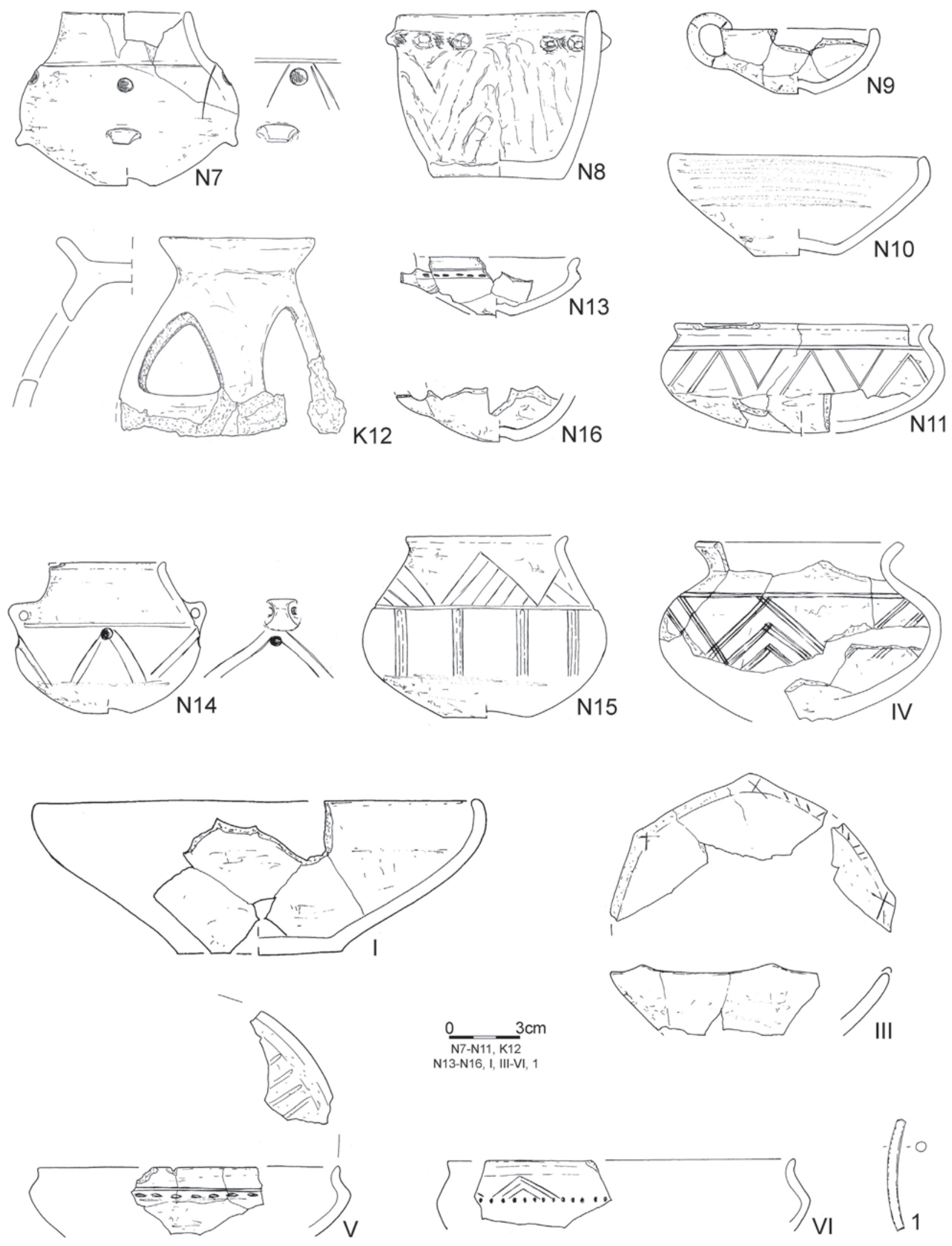

Ryc. 11. Domasław, pow. wrocławski, inwentarz grobu nr 10821. Rys. K. Świątek

Fig. 11. Domasław, Wrocław district, inventory of grave No. 10821. Drawing by K. Świątek 
ogólnie dla okresu halsztackiego, którego koniec wyznacza się na 400 lub 450 r. p.n.e., co obejmuje już częściowo okres następny lateński LT A, przedziały czasowe datowania radiowęglowego dla zespołów z Domasławia (por. Tabela 1) mieszczą się $\mathrm{w}$ rozmaitym zakresie $\mathrm{w}$ przytoczonych, wyznaczanych datach dla tego okresu wczesnej epoki żelaza, głównie starszego podokresu HC. Od tego mamy dwa zaskakujące odstępstwa, a mianowicie gróby nr 1693 (ryc. 6-9) i 10821 (ryc. 10, 11). Trafne wyjaśnienie czasowego następstwa obu zespołów T. Goslara nie rozwiewa bardziej zasadniczej rozterki, jaką datowanie radiowęglowe tych grobów nam stawia. Datowanie tych obiektów sytuuje je w ostatnim V EB okresie epoki brązu. Cechy formalne inwentarza grobowego, w tym ceramika malowana, jednoznacznie kwalifikują je na okres HC wczesnej epoki żelaza. Podobną rozbieżność, trudną do wyjaśnienia otrzymano w przypadku grobu 1801 z Kietrza, choć chodzi o trochę młodszą fazę (Chochorowski 2007, 127-128). Z punktu widzenia archeologicznego postępowania badawcze- go ta rozbieżność, jaką ukazuje datowanie dwóch wspomnianych zespołów z Domasławia, nie da się wytłumaczyć. Nawet sytuując najstarsze daty tych zespołów w wyróżnianym wczesnym okresie halsztackim $\mathrm{HB}_{3}$ (Jacob-Friesen 1973,644), to niezależnie od faktu, że przekraczają one datę 800 p.n.e., stylistycznie inwentarz jest typowy dla form HC. Ten problem zostaje więc jako kolejny otwarty.

Pozostają jeszcze zagadnienia współwystępowania $\mathrm{w}$ inwentarzach grobowych cech formalnych właściwych przeważnie dwom okresom, np. IV/V EB, VEB/HC itp. Powyżej zupełnie trafnie sytuacja ta została w relacjach czasowych wyjaśniona przez T. Goslara i jest całkowicie do przyjęcia, właściwie oczywista. Zjawisko to jest typowe dla przemian kulturowych. W tym procesie częste jest przeżywanie się starszych cech kulturowych, co nie oznacza czasowego starszeństwa ani też jakiegoś wyróżniającego się etapu przejściowego. Uwzględniając to typowe zjawisko, datowanie radiowęglowe zespołów zawierających inwentarze o zróżnicowanych cechach staje się do przyjęcia.

\section{BIBLIOGRAFIA}

Anioła M., Nowaczyk K., Nowaczyk L., Zarzycka A. (2012). Cmentarzysko ludności kultury łużyckiej z epoki brązu na stanowiskach Chrzanów 4 oraz Domasław 10-12, gm. Kobierzyce, woj. dolnośląskie. Raport 2007-2008, t. 1. Warszawa.

Chochorowski J. (1999). Hiperborejczycy wieku brązu - Epoka brązu poza zasięgiem wysokich cywilizacji w Europie. W: J.K. Kozłowski, Encyklopedia historyczna, t. 1. Prehistoria, rozdz. XX (202-246). Kraków: Agencja Publicystyczno-Wydawnicza Opres.

Chochorowski J. (2007). Metodyczne i metodologiczne problemy datowania radiowęglowego pozostałości kremacji z grobów ciałopalnych kultury łużyckiej (na przykładzie materiałów z cmentarzyska w Kietrzu). W: J. Chochorowski (red.), Studia nad epoka brązu $i$ wczesna epoka żelaza. Księga poświęcona Profesorowi Markowi Gedlowi na pięćdziesięciolecie pracy w Uniwersytecie Jagiellońskim (103-138). Kraków: Wydawnictwo Uniwersytetu Jagiellońskiego.

Dąbrowski J., Rajewski Z. (red.). (1979). Prahistoria ziem polskich, t. 4: Od środkowej epoki brązu do środkowego okresu lateńskiego, Wrocław-Warszawa-Kraków-
Gdańsk: Instytut Historii Kultury Materialnej PAN. Ossolineum.

Dąbrowski J. (2009). Polska przed trzema tysiacami lat. Czasy kultury tużyckiej. Warszawa: Wydawnictwo TRIO.

Furmánek V., Mitráš V. (2016). Systems of Periodization Developer and Used to Study the Urnfield Period in Slovakia. W: K. Trybała-Zawiślak, A. Rozwałka (red.), Studies on the Bronze Age and Early Iron Age. Analecta Archaeologica Ressoviensia, 11, 19-48. Rzeszów: Fundacja Rzeszowskiego Ośrodka Archeologicznego, Institute of Archaeology Rzeszów University.

Gardawski A., Woźniak Z. (1979). Podstawy chronologii. W: J. Dąbrowski, Z. Rajewski (red.), Prahistoria ziem polskich, t. 4: Od środkowej epoki brązu do środkowego okresu lateńskiego (22-30). Wrocław-WarszawaKraków-Gdańsk: Instytut Historii Kultury Materialnej PAN. Ossolineum.

Gediga B. (1982). Zagadnienia periodyzacji okresu rozwoju kultury łużyckiej w świetle kontaktów z Południem. W: M. Gedl (red.), Potudniowe pogranicze kultury tużyckiej i powiązania tej kultury z Potudniem (49-58). 
Kraków-Przemyśl: Instytut Archeologii Uniwersytetu Jagiellońskiego i inni.

Gedl M. (1979). Stufengliederung und Chronologie des Gräberfeldes der Lausitzer Kultur in Kietrz. Prace Archeologiczne, 27, Warszawa, Kraków: Uniwersytet Jagielloński.

Gedl M. (1980). Studia nad periodyzacją kultury łużyckiej w południowej części Śląska. Archeologia Polski, 25, 79-129.

Gedl M. (2002). Wielkie cmentarzysko z epoki brązu i wczesnej epoki żelaza w Kietrzu, pow. Głubczyce na Górnym Śląsku. W: M. Gedl (red.), Wielkie cmentarzyska z epoki brazu i wczesnej epoki żelaza (75-116). Warszawa: Komitet Nauk Pra- i Protohistorycznych PAN.

Jacob-Friesen G. (1973). Bronzezeit. W: Reallexikon der Germanischen Altertumskunde, Band 4, Lieferung 5, Sonderdruck (641-648). Berlin - New York: Walter de Gruyter.

Kostrzewski J., Chmielewski W., Jażdżewski K. (1965). Pradzieje Polski. Wrocław, Warszawa, Kraków: Ossolineum.
Kozłowski J.K., Kaczanowski P. (1998). Najdawniejsze dzieje ziem polskich. W: Wielka historia Polski. Kraków: FOGRA Oficyna Wydawnicza.

Krawczuk A. (2000). Grecja. W: K.M. Ciałowicz, J.A. Ostrowski (opracowanie naukowe), Encyklopedia Historyczna Świata, t. II (110-167). Kraków: Agencja Publicystyczno-Wydawnicza Opres.

Kruk J., Milisauskas S., Włodarczak P. (2018). Real Time. Radiocarbon Dates and Bayesian Analysis of the Neolithic Settlement at Bronocice, Fourth Millennium BC. Kraków: Instytut Archeologii Etnologii PAN.

Minta-Tworzowska D. (1994). Klasyfikacja w archeologii jako sposób wyrażania wyników badań, hipotez oraz teorii archeologicznych. Poznań: Wydawnictwo Naukowe UAM.

Purowski T. (2019). Od fajansu do szkła. Kontakty ziem polskich z głównymi centrami cywilizacyjnymi w II-I tyś. p.n.e. $w$ świetle badań archeometrycznych tworzyw szklistych. Warszawa: Instytut Archeologii i Etnologii PAN.

\section{COMMENTS ON DATING AND THE PERIODIZATION OF THE USE OF THE BURIAL GROUND IN DOMASŁAW-CHRZANÓW, WROCŁAW DISTRICT}

After a comprehensive presentation and discussion of the methodology and results of $14 \mathrm{C}$ dating by Professor T. Goslar of bones from the excavated cremation graves at the burial ground located in the two communes of Domasław and Chrzanów (Anioła et al. 2012), I would like to briefly present my comments as an archaeologist about the results. Thanks to the funds obtained as part of the grant project National Science Centre 'Transformations in the burial rite in the Bronze Age and the early Iron Age as an expression of socio-cultural changes in south-western Poland' - contract No. UMO-2014/15/B/HS3/02463 signed on 10.08.2015, we managed to obtain the results of specialist analyses at the Poznan Radiocarbon Laboratory of absolute dating for 50 samples from bone materials from graves found in burial ground in Domasław/Chrzanów. This is an important success for Polish archaeological research. Such analyses have never been carried out on such a large scale. A notable exception is the Neolithic site in Bronocice for which $6014 \mathrm{C}$ datings were made (Kruk, Milisauskas, Włodarczak 2018). However, the value of the results described here is of greater scientific importance. The burial ground in Domasław/Chrzanów was used throughout the Urnfield period distinguished in European prehistory, and in the case of our territory the archaeological Lusatian culture from the middle Bronze Age to the early Iron Age - Hallstatt period. Samples selected for analysis came from all this substantial chronological span, which is of great relevance. Radiocarbon dates from a similar chronological section made at the Laboratory in Kiev come also from a large burial ground excavated by Prof. Marek Gedl for many years in Kietrz, Głubczyce district. This researcher devoted many valuable works to the results he obtained (see Gedl 2002). The extensive commentary and discussion of these results of radiocarbon analyses was published by J. Chochorowski (2007), however, this represents but half of the results obtained from samples analyzed from the burial ground in Domasław/Chrzanów. In both cases, we receive excellent material for comparative studies and reflection on the problems of chronology to which the results of radiocarbon analyses relate. However, before we move on to them, it is still necessary to emphasize the fact that at the current state of research, in the case of both these burial 
grounds we are dealing with sites with a threshold significance for multiple studies on the cultural image of our territory and even Central Europe. For this reason, clarification of the chronological framework of events recognized on the basis of the sources obtained as a result of research at both these sites constitutes a significant event in the history of our research.

For decades laboratory radiocarbon analyses have been offering new opportunities to obtain absolute dates, and not only for the prehistoric periods that interest us in this case. Of course, we realize that the results of these analyses will not make prehistory an event on the order of the calendar dates that we deal with in written history. However, they are becoming an extremely important factor in archaeologists' efforts to overcome the problems of chronology and the periodization of prehistory in many regions of the world and Europe, also for early-historical times.

The results of radiocarbon studies in the case of the burial ground in Kietrz as well as that of Domasław show some discrepancies in dating between radiocarbon dates and dating of particular periods of the Bronze Age and the early Iron Age known from periodization systems for the Nordic circle by $\mathrm{O}$. Montelius and the southern one by P. Reinecke, modified for Polish lands by J. Kostrzewski (1965). This system by J. Kostrzewski in the scope of dating particular periods was later modified for individual regions of Polish lands, as well as the entire territory. Based on the results of research on some sites, e.g., in the burial ground in Kietrz, M. Gedl detailed and modified the periodization system (Gedl 1979; 1980) without going into the dating of phases of a given burial ground's functioning. In 1979, the fourth volume of the Prahistoria Ziem Polskich was published. In it A. Gardawski presents the systems of O. Montelius and P. Reinecke, edited in a tabular manner (Dąbrowski and Rajewski - eds. 1979, 24) in combination with J. Kostrzewski's system from 1965 with the dating of periods of the Bronze Age and the early Iron Age. In 1982 B. Gediga (1982, 49-58, Table 1) presented an attempt at periodization and chronology of the Lusatian culture in Silesia, including comparatively the systems by O. Montelius, J. Kostrzewski and P. Reinecke close to the previously published periodization and the chronology scheme in general for the Bronze Age and the beginning of the early Iron Age by G. Jacob-Friesen (1973, 641-648). Remaining with a few examples of the periodization and chronology of the Bronze Age and the early Iron Age, to provide a broader perspective for further observations on this subject in light of the results of radiocarbon analyses of the burial ground in Domasław, one can still recall the proposal (1998) from the first volume of Wielka historia Polski by J. K. Kozłowski and P. Kaczanowski (1998, 45).
The authors use early dates obtained for the early Bronze Age, also primarily as a result of radiocarbon analyses and, quite generally, arranging the dating of further portions of this period. A year later was published the first volume of the series Encyklopedia historyczna Świata titled Prehistoria, in which (in the chapters dedicated to the Bronze Age and the Iron Age) J. Chochorowski discusses chronology against a broader cultural background, and on page 207, he publishes Figure 249 with a tabular list of chronology and periodization of this section of prehistory according to O. Montelius and P. Reinecke, and on page 210 in Figure 251 he presents, amongst other things, a time frame for the occurrence of Lusatian culture in Central Europe, extending it according to the latest research results from the time of the second period of the Bronze Age $\left(\mathrm{EB}^{1}\right)$ to the La Tène Lta B period (Chochorowski 1999, 206-210). At the end of this brief reminder of several selected studies of chronology and periodization of the Bronze Age and the early Iron Age, mainly in synthetic approaches, it is worth mentioning the already frequently mentioned synthesis of Lusatian culture by J. Dąbrowski (2009, Table 1) in scientific-popular terms in which we find on page 17 Table 1 presenting basic systems of periodization and dating of particular periods. Recently, newer proposals for dating and synchronizing the periodization systems by several Polish authors somewhat burdened with a lower or higher degree of research intuition, were summarized by T. Purowski (2019, 11-13).

When we review the examples provided, we find in them large discrepancies in presentation of absolute dates for individual periods. Similarly, in the case of periodization systems, as in the classic proposals by O. Montelius and P. Reinecke, we also have a large range of proposed modifications by different researchers for individual regions of Europe, who use different terminology such as stages, phases, etc. Mostly, however, they refer to the two classic ones. An excellent illustration of this variety was publish recently by V. Furmánek and V. Mitáš (2016). In relation to the areas of interest in this case, namely Silesia, a comparative tabular list illustrating the dating of individual periods, as well as the attempt to distinguish the phases and stages of cultural transformations taking place during the period of the distinguished Lusatian culture, we find in the aforementioned publication by B. Gediga (1982, Table 1).

In general, after reviewing these several systems, one can say that the differences in the dating of individual periods range between 50 and 100 years. They resulted from attempts to make corrections in relation to Polish lands which assumed some delays, e.g. in relation to the Nordic, South-

1 EB means the Bronze Age for the system by O. Montelius. 
ern, or Hallstatt circles, estimated quite schematically. An illustration of this can be offered by a few selected examples covering the time of the Lusatian Urnfield, from the older Bronze Age to the early La Tène period - i.e., from around 1400 to around the 3rd century BC.

In the case of the proposals by G. Jacob-Friesen (1973, 644-645) and B. Gediga (1982, Table 1), the beginnings of the formation of the Urnfield cultures, including the Lusatian culture, span between 1400 and $1300 \mathrm{BC}$, which means the period $\mathrm{BC}^{2}$ according to P. Reinecke's system and more often from around 1300 to $1200 \mathrm{BC}$, i.e., $\mathrm{BD}$ and III EB (1250-1100 BC) period of the Bronze Age in the northern system by O. Montelius. In J. Kostrzewski's approach for Polish territories, it is the time from about 1200 BC, i.e. III (EB) period of the Bronze Age (1200-1000 BC), which already is placed in the HA period (1200-1000 BC) in the system by P. Reinecke. In the study by A. Gardawski, the BD period is a short time between 1250 and 1200 and it coincides with the final phase of II EB according to J. Kostrzewski, and also includes the beginnings of the III EB according to the northern system by O. Montelius. Jan Dąbrowski in his scheme presenting the system by O. Montelius, P. Reinecke, and J. Kostrzewski gives slightly different absolute dates, which is another confirmation of the aforementioned diversity. In this version, the mid III EB period of the Bronze Age by. J. Kostrzewski would start differently than I tabled $(1965,143)$, i.e., in $1250 \mathrm{BC}$ and reach to $1050 \mathrm{BC}$, which would coincide with dating according to O. Montelius and falls on part of the BD period and part of the HA period according to P. Reinecke. This proposal is also different from the study by A. Gardawski, in which the III EB is the time from 1200 to $1000 \mathrm{BC}$, as in J. Kostrzewski's, and differs from the dates established for this period in the system by O. Montelius, as stated above, and would be placed in the BD period and a significant part of the HA period in the southern system. These discrepancies in dating of individual periods also exist in relation to younger periods, whereas in the case of the IV EB this discrepancy between the system by O. Montelius and J. Kostrzewski reaches 100 years. Leaving aside a detailed analysis of these discrepancies, shown, amongst others on the tables in works by B. Gediga (1982, Table 1), G. JacobFriesen (1973, 644-645), A. Gardawski (Dąbrowski and Rajewski - eds. 1979, 24) and J. Dąbrowski (2009, 17, Table 1) and elsewhere, a few words of commentary need be devoted to the dating of the early Iron Age, important for the site in Domasław.

2 BD, HA, HB, HC, HD mean abbreviations of the Bronze Age and Early Iron Age periods in the southern system by P. Reinecke.
The beginnings of this new Iron Age, the oldest period of which is referred to as the Hallstatt period, are located about 700 BC., and even as 'early Hallstatt' about 750 BC (Jacob-Friesen 1973, 644; Gediga 1982, Table 1). In the northern-Nordic circle we have the continuation of the Bronze Age as the VI EB period. For the Polish territory J. Kostrzewski marks the beginnings of the Hallstatt period for $650 \mathrm{BC}$, taking into account some delay in the inflow of influences from the Hallstatt circle, assessed somewhat schematically, but also there is no greater possibility to act differently. J. Kostrzewski's concept was adopted by A. Gardawski and J. Dąbrowski, and they set a similar time frame for the Hallstatt $\mathrm{HC}$ period in the system by P. Reinecke, which is not totally correct (see Jacob-Friesen 1973, 644).

After recalling and partially commenting on the previous most important archaeological systems of periodization and dating of the periods of the Bronze Age and the early Iron Age, the question arises how to respond to the obtained radiocarbon dating, even using only the larger series which we currently have from the site in Kietrz in Upper Silesia and Domasław in Lower Silesia. In both these regions we observe at this time an analogous rhythm of cultural changes.

To a large extent, we obtain a detailed assessment and interpretation of the dates obtained in the article by Professor Tomasz Goslar (in this volume). An important issue in the face of increase in amount of absolute dates as a result of radiocarbon analyses, the attitude to these results of the archaeologists themselves and the use of these results to refine and improve the periodization and chronology of the various stages of prehistory. In our particular case, from the Middle Bronze Age to the beginning of the next Iron Age, this is a time of a significant weakening of contacts with the Mediterranean civilization circle falling on the so-called Dark Ages (Krawczuk 2000, 112). This means the loss of better grounds for absolute dating, created by the chronology for example of the Aegean civilization circle. The previous divisions have used and continue to use mainly the methods of typological classification (see the detailed, excellent discussion and analysis of classification in archaeology by Minta-Tworzowska 1994) while organizing the facts discovered during excavations in the form of, amongst other matters, permanent features, as well as, above all, movable artefacts. This approach encompasses a relatively low value of intersubjectivity. However, in this way were constructed the basic systems of periodization of the Bronze Age and Iron Age. Also in the case of the burial ground in Domasław, the mainly stylistic transformations of objects constituting grave goods and their comparison with the current criteria of periodization created a base for 
the comparison and synchronization of the periodization constructed in this manner with dates obtained as a result of radiocarbon analyses. This is a task we will face more and more often as research in this field progresses, and we will be surprised by results that cannot be easily synchronized with the previous periodization and chronology of the prehistory. In our particular case, taking into account the significant number of dates obtained, this problem deserves a few words of comment

Generally, comparing the results of radiocarbon studies with the previous dating of particular periods of the Bronze Age and the early Iron Age, it can be said that in the vast majority the dates obtained fall under some parts of the time spans determined for these periods and correctly show the time sequence determined on the basis on stylistic analyses. A similar conclusion could be formulated with reference to the results of testing samples from the Kietrz graves (Chochorowski 2007, 130-132). The dates obtained cover wider extents of time, and we realize that each of the graves from which the sample was analyzed was in fact a one-time event or close in time one. However, as we can see in the case of the burial ground in Kietrz, when the subject of research were samples taken from different depths of the same feature, the dates differ, though they are generally to a greater or lesser degree convergent (Chochorowski 2007, 134-137, List 1, 2).

Analyzing the results listed below in Table 1 produced by Professor T. Goslar, and taking into account their full range for each feature, both listed in different percentage calibration values, as well as compiled in two models A and $\mathrm{B}$, the following comments arise.

The oldest features in the light of these results would be graves No. E 27 (Figs. 1, 2), E 110 (Fig. 3), B109 (Fig. 4), E 220, 2835, 8659 (Fig. 5). The established typological classification (in Table 1 by T. Goslar in the box after B. Gediga), which takes into account stylistic features, contrasts with the radiocarbon dates established for these features and situates them to a large extent in the period of the Tumulus cultures, in Polish territory in the pre-Lusatian culture from II period of the Bronze Age in the periodization by $\mathrm{O}$. Montelius/J. Kostrzewski and BC and BD in the southern periodization system, more appropriate for the areas of south-western Polish territory. The grave complex No. 8659 (Fig. 5) is completely compatible with this classification, and places with these dates and features of the inventory in the time of the Tumulus cultures, although it represents the type of grave common in the Urnfield cultures circle, including the Lusatian culture. The remaining aforementioned grave complexes, based on a typological and stylistic analysis of the inventory originating from them, unfortunately mainly pottery, represent the advanced early phase of the development period of the Lusatian Urnfield with the so-called nodular pottery. In the traditional periodization and chronology scheme, made using the aforementioned criteria and comparative analyses (that is, according to the aforementioned observations), in Polish territory, including Silesia, III EB, i.e., the middle period of the Bronze Age is dated in the O. Montelius/J. Kostrzewski scheme from about $1250 / 1200 \mathrm{BC}$ to $1100 / 1000 \mathrm{BC}$. In the southern system by P. Reinecke it is the $\mathrm{BD}$ and $\mathrm{HA}$ period (Jacob-Friesen 1973, 644; Gediga 1982, Table 1). In slightly different manner this time frame and the periodization of the Bronze Age are presented by A. Gardawski (1979, 24) and J. Dąbrowski (2009, Table 1). At the time of the BD period (Jacob-Friesen 1973, 644) a parallelism of the late Tumulus cultures and the beginnings of the Urnfield cultures is suggested, this stage in the case of Silesia could already include the $\mathrm{BC}_{2}$ period (Gediga 1982, Table 1) and radiocarbon dates would situate these complexes in the initial phase of the formation of the Lusatian Urnfield. Analysis of the style of the inventory coming from these features raises a dilemma, because traditionally these are the characteristics of the developed early stage with nodular pottery. This problem remains to be solved as new results of radiocarbon analyses and studies arise.

We face an almost analogous problem in the case of several grave complexes from the youngest use phase of the burial ground in Domasław from the early Iron Age. In light of the aforementioned time frames determined generally for the Hallstatt period, which ends at 400 or $450 \mathrm{BC}$, which already partially covers the next La Tène LT A period, the time ranges of radiocarbon dating for the complexes from Domasław (see Table 1) fall into a wide range in the dates cited for this period of the early Iron Age, mainly the older HC subperiod. From this we have two surprising deviations, namely grave No. 1693 (Figs. 6-9) and 10821 (Figs. 10, 11). An accurate explanation of the temporal sequence of both complexes by T. Goslar does not disperse the more fundamental dilemma which the radiocarbon dating of these graves creates. Dating of these features situates them in the last V EB period of the Bronze Age. The formal features of the grave inventory, including painted pottery, unambiguously qualify them for the $\mathrm{HC}$ period of the early Iron Age. A similar discrepancy difficult to explain was observed in the case of grave 1801 from Kietrz, although it is from a bit younger phase (Chochorowski 2007, 127-128). From the point of view of archaeological research, this discrepancy, which shows up in the dating of the two complexes from Domasław, cannot be explained. Even placing the oldest dates of these complexes in the distinguished early Hallstatt period $\mathrm{HB}_{3}$ (Jacob-Friesen 1973, 644), regardless of the fact that they exceed the date $800 \mathrm{BC}$, stylistically 
the inventory is typical of $\mathrm{HC}$ forms. Hence, this problem remains, as with many others, open.

There also remains the issue of the coexistence of formal features in grave inventories usually typical of two periods, e.g. IV/V EB, VEB/HC etc.. This situation has been explained quite accurately by $\mathrm{T}$. Goslar in time relations and his explanation is completely acceptable, actually ob- vious. This phenomenon is typical of cultural changes. In this process, the continuation of older cultural characteristics is common, which does not mean temporal seniority or some distinctive transitional stage. Taking this typical phenomenon into account, radiocarbon dating of complexes with inventories with different characteristics becomes acceptable.

Otrzymano (Received): 10.06.2019; Zrecenzowano (Revised): 29.06.2019; Zaakceptowano (Accepted): 7.07.2019

Adres Autora:

Prof. dr hab. Bogusław Gediga

Ośrodek Badań nad Kulturą Późnego Antyku

i Wczesnego Średniowiecza

Instytut Archeologii i Etnologii PAN

ul. Więzienna 6

50-118 Wrocław

e-mail: boguslaw.gediga@gmail.com

(iD https://orcid.org/0000-0003-2334-7202 